\title{
Silent Crickets Reveal the Genomic Footprint of Recent Adaptive Trait Loss
}

Sonia Pascoal ${ }^{1 \dagger}$, Judith E. Risse ${ }^{2,3 \dagger}$, Xiao Zhang ${ }^{4 \dagger}$, Mark Blaxter ${ }^{5,6}$, Timothee Cezard ${ }^{5}$, Richard J. Challis ${ }^{5}$, Karim Gharbi ${ }^{5,7}$, John Hunt ${ }^{8,9}$, Sujai Kumar ${ }^{5}$, Emma Langan ${ }^{5,10}$, Xuan Liu ${ }^{11}$, Jack G. Rayner ${ }^{4}$, Michael G. Ritchie ${ }^{4}$, Basten L. Snoek ${ }^{12,13}$, Urmi Trivedi ${ }^{5}$, Nathan W. Bailey $^{4 *}$

${ }^{1}$ Department of Zoology, University of Cambridge, CB2 3EJ, United Kingdom

${ }^{2}$ Bioinformatics, Department of Plant Sciences, Wageningen University \& Research, 6708 PB Wageningen, The Netherlands

${ }^{3}$ Animal Ecology, Netherlands Institute of Ecology, PO Box 50, 6700 AB Wageningen, The Netherlands

${ }^{4}$ School of Biology, University of St Andrews, St Andrews, Fife KY16 9TH, United Kingdom

${ }^{5}$ Edinburgh Genomics, University of Edinburgh, Edinburgh EH9 3JT, United Kingdom

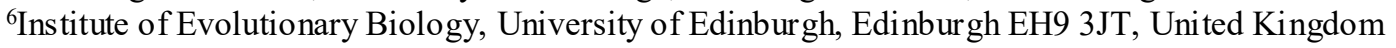

${ }^{7}$ Earlham Institute, Norwich Research Park, Norwich NR4 7UZ, United Kingdom

${ }^{8}$ School of Science and Health and the Hawkesbury Institute for the Environment, Western Sydney University,

Penrith, NSW 2751, Australia

${ }^{9}$ Centre for Ecology and Conservation, University of Exeter, Cornwall Campus, Penryn TR10 9FE, United

Kingom

${ }^{10}$ School of Environmental Sciences, University of East Anglia, Norwich Research Park, Norwich NR4 7UZ,

United Kingdom

${ }^{11}$ Centre for Genomic Research, University of Liverpool, Liverpool L69 7ZB, United Kingdom

${ }^{12}$ Theoretical Biology and Bioinformatics, Utrecht University, Padualaan 8, 3584 CH Utrecht, The Netherlands

${ }^{13}$ Terrestrial Ecology, Netherlands Institute of Ecology, PO Box 50, 6700 AB Wageningen, The Netherlands

$\uparrow$ Contributed equally

* Correspondence: nwb3@st-andrews.ac.uk 
Secondary trait loss is widespread and has profound consequences, from generating diversity to driving adaptation. Sexual trait loss is particularly common 1 . Its genomic impact is challenging to reconstruct because most reversals occurred in the distant evolutionary past and must be inferred indirectly ${ }^{2}$, and questions remain about the extent of disruption caused by pleiotropy, altered gene expression and loss of homeostasis ${ }^{3}$. We tested the genomic signature of recent sexual signal loss in Hawaiian field crickets, Teleogryllus oceanicus. Song loss is controlled by a sex-linked Mendelian locus, flatwing, which feminises male wings by erasing sound-producing veins. This variant spread rapidly under pressure from an eavesdropping parasitoid fly. We sequenced, assembled and annotated the $T$. oceanicus genome, produced a high-density linkage map, and localised flatwing on the $\mathrm{X}$ chromosome. We characterised pleiotropic effects of flatwing, including changes in embryonic gene expression and alteration of another sexual signal, chemical pheromones. Song loss is associated with pleiotropy, hitchhiking and genome-wide regulatory disruption which feminises flatwing male pheromones. The footprint of recent adaptive trait loss illustrates R. A. Fisher's influential prediction that variants with large mutational effect sizes can invade genomes during the earliest stages of adaptation to extreme pressures, despite having severely disruptive genomic consequences.

Male crickets sing to attract and court females and to fight with rivals, but approximately 15 years ago, silent T. oceanicus males arose and spread in populations on the Hawaiian archipelago $^{4,5}$ (Fig. 1a). They were first detected in 2003 in a population on Kauai, where they rapidly spread to near-fixation from undetectable starting frequencies, under selection imposed by a lethal parasitoid fly, Ormia ochracea (Fig. 1b) ${ }^{4}$. Female flies acoustically locate male crickets by eavesdropping on their songs, but silent flatwing males have feminised wings lacking structures used to produce sound and are thus protected (Fig. 1c). The genetic mutation(s) underlying the flatwing phenotype show Mendelian segregation and X-linkage ${ }^{6,7}$, and the propagation of flatwing males to near-fixation in the Kauai population represents one of the fastest rates of evolution known in the wild, having occurred in fewer than 20 generations ${ }^{4}$. All males found in a comprehensive survey of this population in October 2018 were flatwing (38 flatwing males, no normal-wing males found or heard singing by JGR and NWB), but the continued existence of the population indicates that silent males still find mates and must compensate for their inability to sing. The selective environment promoting 
the rapid spread of flatwing crickets is understood, but the mechanistic basis of the phenotype remain an open question. How did such a spectacularly disruptive phenotypic change invade the genome of crickets so quickly? Foundational evolutionary theory predicts that adaptive variants which invade genomes and spread under positive selection should tend to be small in effect size and exert few pleiotropic consequences, although exceptions are predicted during the earliest stages of adaptation ${ }^{8,9}$. Empirical studies have been unable to address this in naturally-evolving systems.

The locus controlling the expression of flatwing morphology could have arisen through de novo mutation(s) coinciding with the time of the phenotype's first observation in 2003, it could have invaded the genome of the Kauai population via migration from an unknown location elsewhere in Hawaii (flatwing morphs have not been observed outside of the Hawaiian islands), or it could have existed for much longer in the population but at extremely low levels, evading detection by researchers. Studies of insecticide resistance in insects and of melanic morphs of Lepidoptera provide some precedent. While some museum specimens collected before the invention of organophosphates have been shown to contain insecticideresistance alleles ${ }^{10}$, in other cases, resistance alleles arose de novo, and also invaded populations and spread under selection ${ }^{11}$. In the peppered moth, a canonical example of rapid evolution in the wild, melanism had a single recent origin approximately corresponding to the start of the industrial revolution ${ }^{12,13}$, but melanic morphs are common in many insects and may persist at low frequencies due to negative pleiotropy, at least until favourable selective conditions occur ${ }^{14}$. In $T$. oceanicus, parasitoid pressure pre-dated the appearance of flatwing in the Kauai population ${ }^{4}$, thus the de novo or introduction scenarios are most plausible.

We studied the genomic signature of song loss in the population on Kauai where flatwing crickets were first discovered, and in which rapid spread has been most thoroughly documented ${ }^{4}$. We sequenced the $T$. oceanicus genome, generating an assembly of $2.045 \mathrm{~Gb}$ consistent with flow cytometry size estimates ${ }^{7}$, with a scaffold N50 of $62.6 \mathrm{~kb}$ (Extended Data Table 1). We established an $\mathrm{F}_{3}$ mapping population using crosses designed to maximise recombination on the $\mathrm{X}$ chromosome, which is only diploid in females (Extended Data Fig. 1). Mapping offspring and parents were sequenced using RADseq, and a map was assembled containing 19 linkage groups. T. oceanicus has a haploid chromosome number of $(13+\mathrm{X})$. We identified linkage group 1 (LG1) as the $\mathrm{X}$ chromosome by applying coverage and 
heterozygosity filters and dummy coding putative X-markers prior to constructing the map. LG1 was the largest linkage group, with a female recombination length of $379 \mathrm{cM}$ and a male length of 195 cM (Extended Data Fig. 2). After resolving chimeric scaffolds (Extended Data Table 2), $35.6 \%$ of the genome was anchored to a linkage map using a LOD5 cutoff (Extended Data Table 3) (Fig. 2a).

We performed gene prediction and annotation using custom pipelines incorporating ab initio, homology, and transcriptome-based approaches (Extended Data Fig. 3). Evidence from different gene prediction and annotation methods was weighted and filtered to predict a final, conservative set of 19,157 genes, 75\% of which had functional annotation (Extended Data Table 4, Extended Data Fig. 4). Gene density was assessed (Fig. 2a track i), and we tested whether the putative $\mathrm{X}$ linkage group showed a different distribution of repeat content relative to the other linkage groups, across eight common categories of repeats. It did not (Fig. 2a track iii, Extended Data Table 5, Extended Data Fig. 5). T. oceanicus gene features were compared to 10 other insect species (Extended Data Table 6), and we contrasted transposable element classifications with three other recently published insect genomes (Extended Data Table 7). The T. oceanicus genome and metadata associated with it are curated in ChirpBase (www.chirpbase.org), a GenomeHubs Ensembl genome browser ${ }^{15}$ that we created as an openly available, community-based genomics resource for researchers working on singing insects.

Flatwing was definitively mapped to the putative X chromosome (Fig. 2b) using markers supported by a LOD10 cutoff and a mixed model, ANOVA-based approach designed to control for uneven genomic relatedness caused by family structure in the mapping crosses. To cope with the particularly high marker association on the putative $\mathrm{X}$ chromosome caused by the Mendelian mode of inheritance of flatwing and the different effective population size of the X compared to autosomes, we identified the QTL using only the top $1 \%$ of markers after FDR correction, yielding a prominent peak occupying approximately one third of the $\mathrm{X}$ chromosome (Fig. 2c). Flatwing morphology is observable in males during mid- to late-instar stages of juvenile development, so we examined early embryonic gene expression differences associated with flatwing. Females carrying the genotype cannot be visually distinguished and embryos cannot be readily sexed, so we used replicate laboratory lines homozygous for flatwing or normal-wing genotypes to detect widespread differential gene expression in the 
developing thoraces of embryonic crickets. We found 830 genes differentially expressed (DE), 204 of which had a $\log _{2}$ fold-change $>1$, and a predominant pattern of down-regulation in flatwing crickets (Extended Data Table 8, Extended Data Fig. 6). DE genes associated with flatwing were widely distributed across linkage groups and unmapped scaffolds (Fig. 2a track iv).

These physically dispersed expression effects suggest that flatwing acts as a master regulatory switch during early development, with a broad cascade of downstream effects. Pathways reconstructed using differential expression data are consistent with such a mode of action. For example adherin junction activity was enriched, which affects epithelial patterning during early development (Extended Data Tables 9 \& 10). Using a stringent and redundant approach combining information from gene sets identified in the QTL study, RNA-seq experiment and a previously-published bulked segregant analysis ${ }^{7}$, we identified 51 annotated protein-coding genes located within LG1 as top flatwing-associated candidates (Extended Data Table 11). GO enrichment analysis indicated that positive regulation of developmental process was overrepresented in this candidate gene set, with three genes in particular (NBL1, GOGA4, UNC89) known to play a fundamental role in the regulation of cell differentiation (Extended Data Table 12).

In most pterygote insects, wings are derived from imaginal discs formed during development by the invagination of embryonic ectoderm ${ }^{16}$. Previous work mainly in Drosophila melanogaster has established that the developmental elaboration of wing venation patterns requires the involvement of numerous transcription factors and complex coordination across numerous signalling pathways ${ }^{17}$. Here, we found that 8 of 51 flatwing associated candidate genes have reported involvement in D. melanogaster wing development. For example, stat $92 E$ expands the proximodistal axis of the wing imaginal disc, subdividing and patterning $i^{18}$. Collier encodes a transcription factor required for wing disc patterning ${ }^{19}$, and Myoglianin expression is required for normal wing disc development ${ }^{20}$. ROR 1 encodes a transmembrane tyrosine-protein kinase receptor involved in phosphorylating MAP kinases ${ }^{21}$, and reduction of MAPK activity through ROR1 silencing can lead to a loss of wing venation phenotype ${ }^{17}$. The protein krasavietz is encoded by $P K R A$, and establishes planar cell polarity in the wing ${ }^{22}$, disruption of which can lead to wing distortion ${ }^{23}$. Knockouts and mutants in Pelle, Gen5, and Plexin-A4 show wing shape and venation alterations with features similar to flatwing ${ }^{24-26}$. 
We tested the consequences of the rapid invasion of flatwing into the $T$. oceanicus genome by focusing on a distinct, close-range sexual signalling modality that operates alongside acoustic signalling in field crickets. Cuticular hydrocarbons (CHCs) are long-chain, waxy molecules expressed on insect cuticles. CHCs are thought to have evolved for dessication resistance, and they tend to be expressed as a bouquet of numerous individual hydrocarbon compounds. T. oceanicus CHCs are sexually dimorphic and function as sexual signals during male and female mate choice ${ }^{27-29}$, and they have been found to vary between flatwing and normal-wing male crickets ${ }^{30}$. We characterised the $\mathrm{CHC}$ profiles of $\mathrm{F}_{3}$ mapping individuals, all of which were raised in a common garden environment, by extracting their $\mathrm{CHCs}$ and using gas chromatography - mass spectrometry (GCMS) to measure the abundance of 26 individual compounds (Fig. 3a) (Extended Data Table 13). By performing dimension reduction using principal components (PC) analysis of the $\mathrm{CHC}$ profiles, we first established that, in our mapping population, males carrying flatwing showed noticeable and significantly different CHC profiles from normal-wing males (Fig. 3b) (multivariate analysis of variance on 6 principal components with eigenvalues $>1$ describing male $\mathrm{CHC}$ blends: $\mathrm{F}_{6,191}=29.769, \mathrm{p}<$ 0.001) (Extended Data Table 14).

QTL analysis was then performed on the first six CHC PCs to determine whether flatwingassociated variation in male $\mathrm{CHC}$ profiles mapped to identifiable genomic regions. The putative X chromosome, LG1, was of particular interest, because we hypothesized that the striking variation between $\mathrm{CHC}$ profiles of flatwing and normal-wing males could be a pleiotropic effect of flatwing. Genetic mapping of $\mathrm{CHCs}$ was performed blind to male morphotype. PC1, which explained over a third of the variance in male $\mathrm{CHC}$ profiles, mapped to a ca. $2.5 \mathrm{cM}$ region strongly co-localised with flatwing (Fig. 3c). PCs 4 and 6 also had co-localizing peaks (Extended Data Fig. 7). As dimension reduction for CHCs can obscure phenotypic patterns in the original individual chemical compounds, we mapped each of the 26 compounds separately. Of these, 9 showed significant peaks co-localising with flatwing (Fig. 3d). We recovered no autosomal QTL peaks for PCs 1-6, and only one QTL peak for one compound on one autosome (compound 11, 7-C31 ene, on LG8). However, the latter peak was weakly supported, with only a single marker showing an association at FDRcorrected $\mathrm{p}<0.001$. 
We interrogated genes on scaffolds under the CHC QTL peaks following a similar procedure used to produce the flatwing candidate gene set (Extended Data Table 15). Of 55 proteincoding genes, a subset of 6 were implicated for every CHC trait with a significant QTL peak, and these 6 genes were also present in the flatwing candidate gene set. These are strong candidates for testing the pleiotropic consequence of evolved acoustic sexual signal loss on chemical sexual signals. Our final step was to explore the nature of the phenotypic shift in flatwing male CHC profiles. It is unknown how flatwing males' profiles compare to those of females ${ }^{30}$, but given the generally feminising effect of flatwing on male wing morphology, we predicted that flatwing males' CHC profiles would also be feminised. We compared them to the profiles of normal-wing males and females using discriminant function analysis on profiles from all three groups. Discriminant function 1 (eigenvalue $=2.526$ ) explained $78.8 \%$ of the variance, and indicated that flatwing male crickets' CHC profiles are strongly feminised (Fig. 3e). Their CHCs appear to be correspondingly less attractive to females ${ }^{31}$.

The rapid emergence and spread of flatwing crickets on Kauai has been described as one of the fastest rates of evolutionary adaptation ever documented in the wild ${ }^{32}$. Nearly a century ago in 1930, R. A. Fisher ${ }^{8}$ developed a 'geometric' model that describes the genomic landscape of such early-stage adaptation and predicts what mutational features are associated with adaptive change. In doing so, he reconciled the prevailing, gradualist view of evolution with seemingly inconsistent units of discrete Mendelian inheritance that were being discovered and characterised at the time. Fisher's key insight was that the process of evolutionary adaptation tends to favour mutations of small effect, with impacts narrowly limited to the phenotypic variants directly under selection ${ }^{33}$. However, he built exceptions to this general rule into his model when selection is severe, and the genomic signature of song loss in Hawaiian T. oceanicus uniquely confirms and illustrates this insight. Adaptation was recent, abrupt and proceeded rapidly in this system. Prior work on T. oceanicus has found differences in the level of phenotypic plasticity, gene expression, and other reproductive characteristics such as male testis size between male normal-wing and flatwing genotypes ${ }^{34-}$ ${ }^{36}$, and our present findings reveal the genomic footprint of strong, associated effects on sexual signalling in an entirely different sensory channel. These consequences of rapid adaptive trait loss are early-acting, genome-wide, and impact a range of important fitness traits. The suite of characters affected in flatwing crickets is reminiscent of feminised alternative male morphs in ruff (Calidris pugnax) in which supergene architecture controls 
size, ornament and behavioural traits simultaneously ${ }^{37}$, and in feminised bulb mites ${ }^{38}$. What is surprising is that an evolved loss of function could lead to such similarly wide-ranging phenotypic impacts so quickly. The genomic signature of recent, rapid trait loss in $T$. oceanicus confirms Fisher's predictions about adaptive evolution - by demonstrating the exception to his rule.

\section{METHODS}

Cricket rearing and maintenance. Laboratory stocks of Teleogryllus oceanicus were established from eggs laid by wild-caught females from a population on the Hawaiian island of Kauai in 2012, and a population near Daintree, Australia in 2011. Stocks were maintained in the laboratory within 16 L plastic containers containing cardboard egg cartons for shelter. All crickets were reared in a single, temperature-controlled chamber a $25^{\circ} \mathrm{C}$, on a 12:12 light:dark cycle. They were maintained regularly and fed ad libitum with Burgess Excel Junior and Dwarf rabbit pellets and provided water in a moist cotton pad that also served as an oviposition substrate. Throughout all experiments, all crickets were reared in a common-garden environment in the same temperature-controlled chamber.

Genome sequencing. Three Illumina sequencing libraries were prepared using genomic DNA extracted from the head capsule and muscle tissue of a single $T$. oceanicus female using a DNeasy Blood \& Tissue kit (Qiagen). The female was sourced from the Kauai stock population. gDNA was quality-checked using Nanodrop and Qubit prior to Illumina library preparation and sequencing at Edinburgh Genomics. We prepared three standard paired-end TruSeq libraries with insert sizes of 180 bp, $300 \mathrm{bp}$, and $600 \mathrm{bp}$. We supplemented reads from the above three Illumina libraries with additional sequences from two TruSeq Nano Pippin selected libraries with insert sizes of $350 \mathrm{bp}$ and 550 bp, one 8 kb Nextera gel-plus mate-pair library, and 1 PacBio library. For these libraries, gDNA from a separate, single female cricket from the same laboratory population was extracted using a high molecular weight Genera Puregene Cell Kit (Qiagen). The first three TruSeq libraries were sequenced on 5 lanes of an Illumina HiSeq 2000 v3 to yield 100 bp paired-end reads. NanoPippin libraries and the Nextera mate-pair library were sequenced on 2 Illumina HiSeq 2500 lanes to yield 250 bp pairedend reads. To construct the PacBio library, we purified the extraction with 1x AMPure beads (Agencourt) and performed quality control using Nanodrop and Qubit. Average DNA size and degradation was assessed using a high sensitivity genomic kit on a fragment analyzer. Size-selected and non-size-selected libraries were made by shearing gDNA using g-TUBEs (Covaris). Size selection was performed using the BluePippin DNA Size Selection System with $0.75 \%$ cassettes and cutoffs between 7 and $20 \mathrm{~kb}$. Preparation of both libraries then proceeded using the same protocol. We treated DNA for $15 \mathrm{~min}$ at $37^{\circ} \mathrm{C}$ with Exonuclease V11. DNA ends were repaired by incubating 
for 20 min at $37^{\circ} \mathrm{C}$ with Pacific Biosciences damage repair mix. Samples were then incubated with end repair mix for $5 \mathrm{~min}$ at $25^{\circ} \mathrm{C}$ followed by washing with $0.5 \mathrm{x}$ AMPure and $70 \%$ ethanol. DNA adapters were ligated overnight at $25{ }^{\circ} \mathrm{C}$. Incubation at $65{ }^{\circ} \mathrm{C}$ for $10 \mathrm{~min}$ was used to terminate ligation reactions, and then samples were treated with exonuclease for $1 \mathrm{hr}$ at $37^{\circ} \mathrm{C}$. We purified the SMRTbell library using $0.5 x$ AMPure beads and checked quality and quantity using Qubit assays. Average fragment size was quantified using a fragment analyser. For sequencing, primers were annealed to the SMRTbell library at values determined using PacBio's Binding Calculator. A complex was formed using DNA polymerase (P6/C4 chemistry), bound to MagBeads, and then used to set up 43 SMRT cells for sequencing to achieve 10X coverage. Sequencing was performed using 240 min movie times.

Genome assembly. Raw reads from all Illumina libraries were trimmed using cutadapt v.1.8.3 ${ }^{39}$ to remove adapters, primers and poor quality bases, and then error-corrected using BLESS ${ }^{40}$. PacBio reads $<1,000 \mathrm{bp}$ were discarded. The original fragment length of the $350 \mathrm{bp}$ library was shorter than the sequenced paired read length of 500bp, so reads from this library were merged using Vsearch v.1.10.1 $1^{41}$. Platanus v.1.2.4 $4^{42}$ was used to assemble error-corrected reads from all Illumina libraries except the mate-pair library; reads from the latter were added at the scaffolding stage. Next, we selected the contigs $>1,000$ bp and combined these with the PacBio data to generate a hybrid assembly using PBJelly v.15.2.20 $20^{43}$. Pilon v.2.14 ${ }^{44}$ was used to improve local base accuracy, and BUSCO v. $2.1^{45}$ was used to assess genome quality through gene completeness.

Repeat annotation. We used de novo and homology-based approaches to identify repetitive regions. We first built a de novo repeat library using RepeatModeler ${ }^{46}$, with dependencies RECON and RepeatScout ${ }^{47}$. To scan and classify interspersed repeats and low complexity DNA sequences at the DNA level, we searched the cricket genome sequence against the Dfam consensus database ${ }^{48}$, RepBase $^{49}$, and the de novo repeat library using RMBlast ${ }^{50}$ and RepeatMasker ${ }^{51}$. Protein-level repeats were identified by searching against the TE Protein Database using RepeatProteinMask ${ }^{51}$. Unclassified repetitive elements were further classified by TEclass ${ }^{52}$, a programme using a support vector machine learning algorithm. Tandem repeats were also identified in the cricket genome using Tandem Repeat Finder ${ }^{53}$.

Gene prediction. Before running gene prediction pipelines, repetitive regions identified above were masked using an in-house Perl script. We built a pipeline including ab initio, homology and transcriptome-based methods to predict protein-coding genes in the cricket genome (Extended Data Fig. 3). For ab initio prediction, $\mathrm{SNAP}^{54}$, Glimmer-HMM${ }^{55}, \mathrm{GENEID}^{56}$, and BRAKER1 ${ }^{57}$ were used to generate preliminary gene sets from the repeat-masked genome. Specifically, reads obtained from the $T$. oceanicus transcriptome were aligned against the repeat masked genome with TopHat $2^{58}$. SAMTOOLS ${ }^{59}$ was used to sort and index the resulting Binary Alignment Map (BAM) format file. 
This BAM file was processed in BRAKER $1^{57}$, which used transcriptome data to train GENEMARK$\mathrm{ET}^{60}$, generate initial gene structures, and then subsequently train AUGUSTUS ${ }^{61}$ and finally integrate RNA-seq information into final gene predictions. For other $a b$ initio gene prediction programmes, gene sets from Locusta migratoria ${ }^{62}$, Acyrthosipon pisum ${ }^{63}$, and Drosophila melanogaster ${ }^{64}$ were used for model training. For homology-based prediction, we aligned protein sequences of five insect species (L. migratoria ${ }^{62}$, Drosophila melanogaster, Anoplophora glabripennis ${ }^{65}$, Nilaparvata lugens $^{66}$, and Cimex lectularius $\left.{ }^{67}\right)$ to the repeat-masked cricket genome using TBLASTN $\left(\mathrm{E}<10^{-5}\right)^{50}$. The boundaries of potential genes were further identified using BLAST2GENE ${ }^{68}$. We then ran GENEWISE2 ${ }^{69}$ to obtain accurate spliced alignments and generate a final, homology-based gene set. For prediction based on transcriptome data, the de novo transcriptome assembly generated by Trinity ${ }^{70}$ was filtered based on gene expression level, and then passed to Program to Assemble Spliced Alignments (PASA) $)^{71}$. PASA performed transcript alignments to the cricket genome, generated a new transcript assembly, and predicted gene structures. All gene sets predicted by ab initio, homology, and transcriptome-based methods were then combined into a weighted consensus gene set using EVidenceModeler $(E V M)^{72}$. We removed genes likely to be spurious, those with low EVM support, partial genes with coding lengths shorter than $150 \mathrm{bp}$, and genes only supported by a minority $(\leq 2)$ of $a b$ initio methods $^{73}$. PASA was used to further update the filtered consensus gene set to produce a finalised official gene set. The completeness of this final gene set was assessed by both BUSCO v.2.1 (using the arthropoda dataset) ${ }^{45}$ and transcriptome data.

Functional assignment. Putative gene functions were assigned based on InterPro ${ }^{74}$, SwissProt ${ }^{75}$, $\mathrm{TrEMBL}^{75}$ and RefSeq non-redundant (NR) protein and Kyoto Encyclopedia of Genes and Genomes (KEGG) gene databases. Briefly, we first obtained protein sequences from the final gene set using $\mathrm{EVM}^{72}$. Functional annotation and gene ontology terms were assigned to genes based on protein sequence, using InterProScan $5^{76}$. These proteins were also blasted against SwissProt, TrEMBL and NR databases (PLASTP, E $<10^{-5}$ ), and assigned their best hits as functional annotations. Gene ontology (GO) terms were assigned using GO annotations downloaded from the GO Consortium ${ }^{77,78}$. BLAST2 $\mathrm{GO}^{79}$ was implemented to further assign unassigned genes using NCBI databases, and KEGG Orthology $(\mathrm{KO})$ terms were assigned using BlastKOALA ${ }^{80}$.

Genome anchoring. ALLMAPS ${ }^{81}$ was used to detect chimeric scaffolds, anchor the cricket genome to the linkage map (see below), and construct pseudo-molecules (reconstructed portions of chromosomal sequence). We first built a consensus genetic map based on male and female genetic distances obtained from linkage maps, in which equal weighting was applied for both sexes. Then, scaffolds for which more than four markers mapped to multiple linkage groups were designated as chimeric scaffolds, and split. After this correction was applied, scaffolds anchored to the linkage maps were oriented and ordered based on the consensus genetic map. We used a custom Perl script to order 
unanchored scaffolds according to their length, and liftOver ${ }^{82}$ to convert genome coordinates based on anchoring results.

Genome browser development (ChirpBase). We created ChirpBase, an open-access community genomics resource for singing insects, such as field crickets and katydids. The resource can be accessed at www.chirpbase.org where users may view and download genomic data and scripts presented in this study in addition to uploading data. An index page links to an ensembl page, where assembly statistics can be visualised using a Challis plot or compared in tabular format. A plot illustrating codon usage is presented, as well as a visualisation of BUSCO scores. Additional pages linking from this include a basic local alignment search tool (BLAST) page and a download page where raw data can be accessed. We used the GenomeHubs framework to set up ChirpBase ${ }^{14}$. Briefly, the databased is hosted using a Linux container (LXC) on a remote computer, linked to a cluster via an intermediate import computer. A MySQL docker container was started in the LXC, where a database ini file resided to guide additions to the database. An Ensembl-easy mirror Docker container was run to import the database into the MySQL container, uploading data designated in the ini file from the LXC to the database. The MySQL container links to an Ensembl EasyMirror container, BLAST container, and a download container.

Linkage and QTL mapping crosses. We constructed a linkage map for T. oceanicus using a series of crosses to maximise recombination on the X chromosome (Extended Data Fig. 1), combined with restriction-site associated DNA sequencing (RAD-seq) to identify markers. Flatwing segregates on the $\mathrm{X}$ chromosome in both Kauai and Oahu populations ${ }^{6,7}$, so mapping was performed with $\mathrm{F}_{3}$ offspring to increase recombination on the $\mathrm{X}$. We set up two parental mapping families by crossing a flatwing sire from the Kauai population with a virgin dam from the Daintree, Australia population. Daintree females were used in the cross because flatwings do not exist in that population, and other sexually-selected traits such as song and cuticular hydrocarbons show significant divergence between Australian and Hawaiian populations ${ }^{83}$, which maximised our opportunity to genetically map segregating variation in other phenotypes. Female $F_{1}$ offspring from parental crosses were heterozygous for flatwing, enabling recombination on the X. Full-sib matings were then performed with $F_{1}$ males, all of which were normal-wing. The resulting $F_{2}$ female offspring were a segregating mix of homozygous normal-wing genotypes on the $\mathrm{X}$, or heterozygous with respect to wing morph. Recombination between flatwing and normal-wing genotypes was similarly possible in the heterozygous $\mathrm{F}_{2}$ females, but their phenotype is not externally detectable. To further increase recombination on the $\mathrm{X}$, we performed another generation of crossing by mating $\mathrm{F}_{2}$ females with fullsib flatwing males from the same generation. Screening male morph types in the resulting $\mathrm{F}_{3}$ offspring enabled us to identify $\mathrm{F}_{2}$ crosses involving heterozygous females, as all male offspring of homozygous normal-wing females expressed normal-wing morphology. The crossing procedure 
resulted in $10 \mathrm{~F}_{3}$ mapping families from the original two parental families, for a total of 192 females, 113 normal-wing males, and 86 flatwing males.

Marker identification using RAD-seq. RAD-seq was used to identify single nucleotide polymorphisms (SNPs) in $F_{3}$ offspring $(n=391), P_{0}$ dams and sires $(n=4)$, and the $F_{2}$ sires and dams $(n=19)$ that were used to produce mapping individuals in the $F_{3}$ generation. For each individual, gDNA extraction and quality control was performed as described above prior to library preparation. gDNA was digested using SbfI (New England BioLabs). We barcoded individuals by ligating P1 adapters $(8 \mathrm{nM})$, then sheared and size selected $300-700$ bp fragments. After ligating P2 adapters to sheared ends, parents were sequenced to an average coverage of $120 \mathrm{x}$ and offspring to $30 \mathrm{x}$ on an Illumina HiSeq 2000.

Construction of linkage map. Reads from all paired end RAD libraries were demultiplexed by sample using process_radtags from Stacks ${ }^{84}$, mapped against the reference genome assembly using BWA-MEM ${ }^{85}$ and duplicates marked using PicardTools MarkDuplicates (http://broadinstitute.github.io/picard). Variants were called using samtools mpileup (version 1.3, parameters -d 2000 -t DP,DPR,DV,DP4,SP -Aef -gu) and bcftools call (version 1.3, parameters -vmO $\mathrm{z}-\mathrm{f}$ GQ). The resulting variants were filtered using vcfutils.pl (included with bcftools) with minimum quality 50 and a minimum read depth of 150 (-Q 50 -d 150) to only retain high quality variants. The $\mathrm{vcf}$ format was converted to the required lepmap2 input format using a custom script of the RADmapper pipeline (RAD_vcf_to_lepmap_with_sexmarker_conversion.py, https://github.com/EdinburghGenomics/RADmapper). During this conversion samples that did not fit relatedness expectations and samples from family $\mathrm{J}$ (which lacked a genotyped father) and P0 parents were excluded from linkage map creation. Putative X-linked markers (male_het $<=1$, female_het $>$ 20 , het_sire $<=1$ ) were converted to biallelic markers in the relevant male offspring and sires using a dummy allele (Extended Data Table 17). The linkage map was then created using the following steps and parameters in lepmap2 (Filtering: dataTolerance 0.05 keepAlleles $=1$; SeparateChromosomes: losLimit $=10$ sizeLimit $=10$ informativeMask $=3$;JoinSingles: lodLimit $=5$;OrderMarkers: filterWindow=10 polishWindow $=100$; OrderMarkers evaluateOrder: filterWindow $=10$ polishWindow=100). The resulting linkage map files were merged with the marker and sample information using a custom script from the RADmapper pipeline (LG_to_marker.py).

QTL mapping. To identify the flatwing locus on the putative X chromosome (LG1), we performed ANOVA for each marker using the $\mathrm{lm}$ package in $\mathrm{R}$ (v. 3.1). Individual p-values were corrected to account for multiple testing using Bonferroni correction and markers supported by a LOD10 cutoff were plotted. QTL for all 26 cuticular hydrocarbon ( $\mathrm{CHC}$ ) peaks as well as the principle components from the CHC analysis were mapped to the linkage groups using mixed linear models in ASReml 4. Mapping used a GWAS-type approach, taking into account genetic relatedness between individuals ${ }^{86}$. 
The markers mapped to the autosomal linkage groups 2-19 were filtered to contain only bi-allelic SNP markers with a MAF $<=0.01$ and $<5 \%$ missing samples per marker. In addition, all grandparental, parental and female samples were removed together with samples that clustered with the wrong family or did not have $\mathrm{CHC}$ data. Only male samples were selected, as our aim was to map male CHCs (not sex-related associations) on the putative X (LG1) and autosomes using principle components from the $\mathrm{CHC}$ analysis as well as individual compounds as traits. The remaining 21,047 markers were used to calculate pairwise genetic relatedness with the first normalisation ${ }^{87}$. The resulting inverse relatedness matrix was used as random effect in a model: $\mathrm{CHC}$ trait $\sim$ mu marker $\mathrm{r}$ ! Giv(animal). P-values for all markers were extracted from the results and corrected for multiple testing using Bonferroni correction. The same model was used to assess LG1 separately with the same set of samples, for which 6,537 markers were used after filtering.

Pure-breeding lines and embryo sampling for RNA-seq. Lines homozygous for the flatwing and normal-wing genotypes were produced following previously described methods ${ }^{34}$. Briefly, one generation of crosses was performed, starting with the laboratory population derived from Kauai and crossing males of either wing phenotype to virgin females of unknown genotype. Because the phenotypic effects of flatwing are sex-limited, family-level screening of the resulting male offspring was performed to select homozygous flatwing and homozygous normal-wing lines, resulting in a final selection of three pure-breeding lines for each morph genotype. Developing embryos were sampled from eggs laid by females from each line. Females were maintained in laboratory culture as above, and their oviposition substrates were monitored. Eggs were removed from the substrate and immediately preserved in $500 \mu \mathrm{L}$ of RNAlater (Qiagen) at the stage when eye pigmentation first develops, ca. 2 weeks after laying. This time point corresponds approximately to embryonic stage 1314 in the related grylline species Gryllus bimaculatus ${ }^{88}$. After removing the outer egg chorion, the thoracic segment of each nymph was microdissected. Nymphs cannot be sexed based on external morphology until a later stage of juvenile development, and as chromosomal sex determination is $\mathrm{XX} / \mathrm{XO}$, screening for sex-specific markers is not possible. To minimise potential variation in sex ratio of samples between lines, and ensure a sufficient volume of tissue to extract RNA, thoracic tissue from $\mathrm{n}=8$ nymphs was pooled for each replicate, and 6 biological replicates were produced for each morph type (2 per line).

RNA-seq and gene expression profiling. Total RNA was extracted using the TRIzol plus RNA purification kit (Life Technologies) and DNAse treated using PureLink (Invitrogen). RNA was quantified and quality checked using Qubit assessment (Invitrogen) and Bioanalyser RNA Nano Chips (Agilent), respectively. To isolate mRNA we depleted samples with RiboZero. After verifying depletion, cDNA libraries were constructed using the ScriptSeq protocol (Epicentre) with AMPure XP beads for purification. Following barcoding and multiplexing, final quality was checked and qPCR performed using Illumina's Library Quantification Kit (Kapa). Sequencing was performed on an 
Illumina HiSeq 2000 v3, with 1\% PhiX DNA spike-in controls to produce 100 base paired-end reads. CASAVA v.1.8.2 was used to demultiplex reads and produce raw fastq files, which were then processed with Cutadapt v.1.2.1 $1^{38}$ and Sickle v. $1.200^{89}$ to remove adaptor sequences and trim lowquality bases. Further quality assessment was performed in FastQC. Expression analysis of RNA-seq data was performed broadly following the protocol published by Pertea et al. (2016) ${ }^{90}$. Reads were aligned to the genome using HISAT2 with strand-specific settings, and transcripts compiled for each sample in StringTie, using the gene annotation file as a reference, which were then merged across all samples to produce a single annotated reference transcriptome. Sample transcript abundances were estimated with the parameter -e specified to restrict abundance estimation to annotated transcripts. Differential expression analysis was performed at the gene level following normalisation of counts by trimmed mean of M-values (TMM), using a generalised linear model (GLM) with negative binomial distribution and a single predictor variable of 'morph' in the edgeR package ${ }^{11}$ in R v.3.4.1. Only genes with an expression level greater than 1 count per million in at least 3 samples were included in the analysis. Significance-testing was performed using likelihood ratio tests, and genes were considered significantly differentially expressed between morph genotypes if FDR-adjusted P-values were below a threshold of 0.05 .

Screening for top candidate genes associated with flatwing. We adjusted $P$-values for significant marker associations in the flatwing QTL mapping procedure using Bonferroni correction with a cutoff of $P<0.001$. Three sources of information were used to comprehensively and robustly detect a set of top candidate genes associated with the flatwing phenotype. We detected genes (i.e. any overlapping portion of a predicted gene sequence cf. Extended Data Table 6) located in $1 \mathrm{~kb}$ flanking regions of all significant QTL markers after FDR correction as above, and defined these as QTLassociated candidates. We then subsetted these genes to retain only those located in the $1 \mathrm{~kb}$ flanking regions of the most significant (top 1\%) of all QTL markers, and defined these as Top 1\%-associated candidates. We also obtained the flatwing-associated sequences from a previously published bulk segregant analysis (BSA) of Kauai flatwings ${ }^{7}$, and defined the BSA reference sequences containing flatwing-associated SNPs as flatwing-associated BSA sequences. We mapped these BSA sequences to the $T$. oceanicus reference genome using BWA-MEM with default parameters ${ }^{85}$. Coordinates of mapped sequences were extracted from the resulting BAM files using SAMTOOLS ${ }^{59}$ and custom Perl scripts, and we only retained those sequences that were anchored to LG1. Genes within $1 \mathrm{~kb}$ of these retained sequences were defined as BSA-associated candidates. Finally, we extracted differentially expressed genes from the embryonic thoracic transcriptome analysis above, and defined these as DEG-associated candidates. To ensure a reliable final candidate gene set for flatwing, we only retained genes supported by at least two of these four gene sets. We used KEGG pathway mapping (colour pathway) to reconstruct pathways and obtain reference pathway IDs ${ }^{92}$. To characterise significantly enriched GO terms and KEGG pathways in DEGs, we implemented the hypergeometric 
test in enrichment analyses. $P$ values for each GO and KEGG map term were calculated and FDRadjusted in $\mathrm{R}$.

Cuticular hydrocarbon extraction and gas chromatography-mass spectrometry. We extracted $\mathrm{CHCs}$ from $\mathrm{F}_{3}$ mapping individuals prior to extracting gDNA for RADseq. Extraction and analysis of CHCs followed previous methodology ${ }^{83}$, which is briefly described here. Subjects were flash-frozen for several minutes at $-20^{\circ} \mathrm{C}$ and then thawed. They were individually placed into $4 \mathrm{~mL}$ borosilicate glass vials (QMX Laboratories) and immersed for 5 minutes in $4 \mathrm{~mL}$ of HPLC-grade hexane (Fisher Scientific), then removed from the vials and stored for later processing. We evaporated a $100 \mu \mathrm{L}$ aliquot of each sample overnight in a $300 \mu \mathrm{L}$ autosampler vial (Fisher Scientific). CHC extracts were transported to the University of Exeter for gas chromatography mass spectrometry (GC/MS) using an Agilent $7890 \mathrm{GC}$ linked to an Agilent 5975B MS. Extracts were reconstituted in $100 \mu \mathrm{L}$ of hexane with a $10 \mathrm{ppm}$ pentadecane internal standard, and $2 \mu \mathrm{L}$ of this was injected into the GC/MS using a CTC PAL autosampler at $5{ }^{\circ} \mathrm{C}$. The carrier gas was helium and we used DB-WAX columns with a 30 $\mathrm{m} \times 0.25 \mathrm{~mm}$ internal diameter and $0.25 \mu \mathrm{m}$ film. Injection was performed in split-less mode. The column profile was optimised for separation of the $\mathrm{CHC}$ extract ${ }^{83}$ to start at $50{ }^{\circ} \mathrm{C}$ for 1 minute, followed by a temperature ramp of $20^{\circ} \mathrm{C}$ per minute until finally holding at $250{ }^{\circ} \mathrm{C}$ for a total run time of 90 minutes. The inlet temperature was $250^{\circ} \mathrm{C}$ and the MS transfer line was $230{ }^{\circ} \mathrm{C}$. We recorded electron-impact mass spectra using a $70 \mathrm{eV}$ ionization voltage at $230{ }^{\circ} \mathrm{C}$, and a $\mathrm{C}_{7}-\mathrm{C}_{40}$ alkane standard was run as a standard to enable the later calculation of peak retention indices.

Quantification and analysis of CHC profiles. For each individual, we used MSD CHEMSTATION software (v.E.02.00.493) to integrate the area under each of 26 CHC peaks (Extended Data Table 13) following Pascoal et al. (2016) ${ }^{83}$. Peak abundances were standardized using the internal pentadecane standard and $\log _{10}$ transformed prior to analysis. After accounting for samples that failed during extraction or during the $\mathrm{GC}$ run $(\mathrm{n}=9)$, plus one normal-wing male $\mathrm{CHC}$ profile that was identified as an outlier and removed during analysis (Extended Data Fig. 8), we analyzed a total of $n=86$ flatwing males, $n=112$ normal-wing males, and $n=185$ females of unknown genotype. To test whether CHC profiles differed between males of either wing morph, we first performed dimension reduction using principal components analysis (PCA) on male data only. JMP Trial 14.1.0 (SAS Institute Inc.) was used to draw a 3D scatterplot of the first three PCs. To assess statistical significance, we performed a MANOVA using all principal components with eigenvalue $>1.00(n=6)$. This indicated a highly significant difference among male morphs which formed the basis of QTL mapping described above. To visualise the difference between flatwing and normal-wing male $\mathrm{CHC}$ profiles with respect to female CHC profiles, we performed a discriminant function analysis (DFA) for all samples and all 26 peaks. DFA highlights the maximal difference between pre-defined groups, with maximum group differences indicated by the first DF axis. Statistical analyses of CHC data were done in SPSS (v.23). 
Data Availability. Raw reads from Illumina and PacBio genome sequencing libraries, embryo RNAseq reads, RADseq reads used in the linkage map and QTL analyses, CHC phenotype data will be made publicly available upon acceptance. Custom scripts are available online at http://www.chirpbase.org if not stated otherwise. 


\section{Figures}

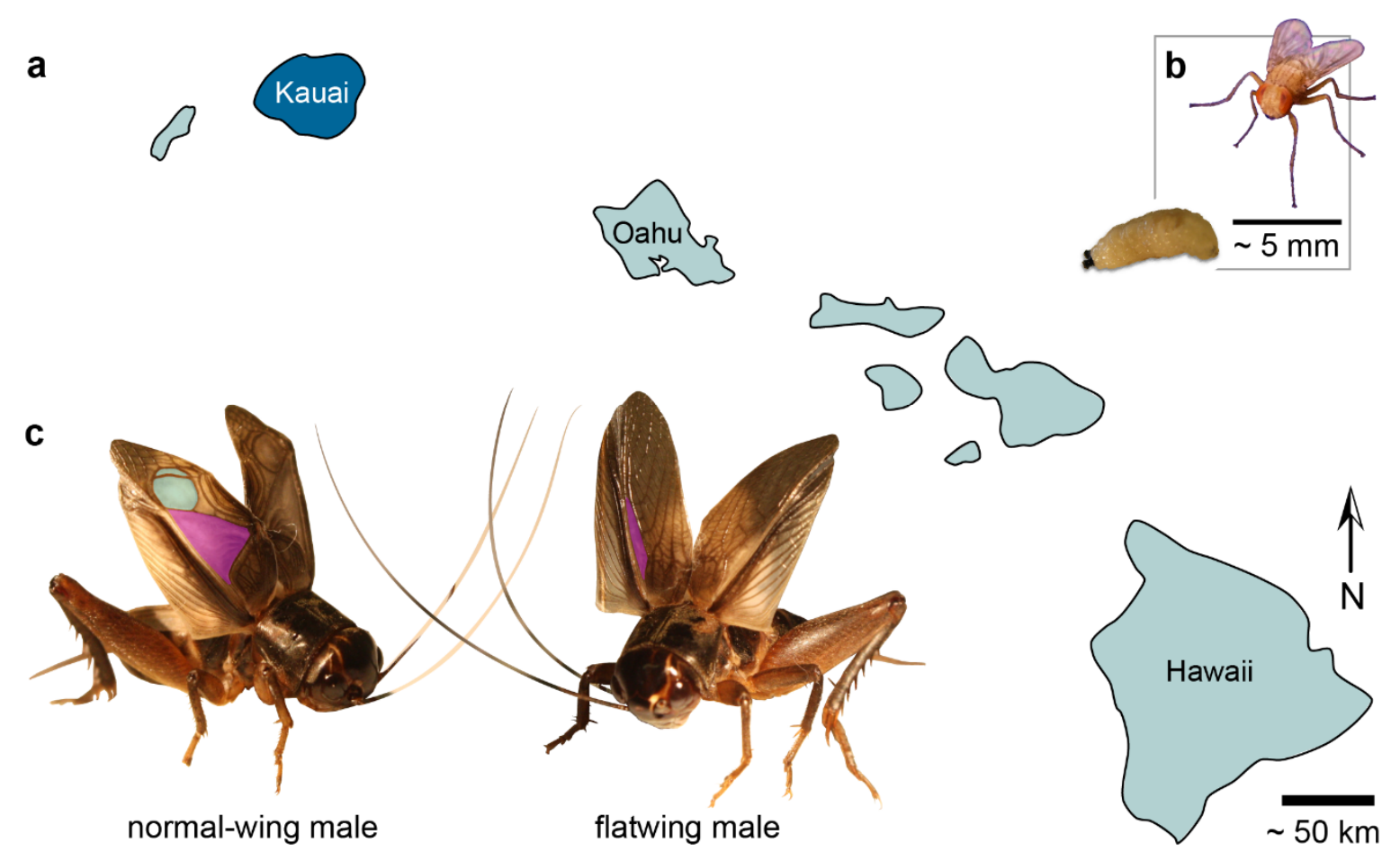

Fig. 1 | Rapid evolutionary loss of song in Hawaiian crickets. a, The field cricket $T$. oceanicus is thought to have migrated to the Hawaiian archipelago from other islands in Oceania, and is attacked by the fatal, acoustically-orienting parasitoid fly Ormia ochracea on Kauai, Oahu and Hawaii. We studied crickets from a population in Kauai, highlighted in dark blue, where parasitoid infestation rates have historically been highest. b, Adult female fly and mature parasitoid larva. Gravid female flies locate hosts by eavesdropping on singing male crickets, then they eject larvae that burrow into the host and consume its viscera before emerging to pupate. Infestation is fatal, and the flies exert significant natural selection against male song. c, Normal-wing males (left) of this field cricket species produce advertisement, courtship and aggressive songs by elevating and rubbing together forewings that bear specialised sound-producing venation. A toothed file on the right wing engages with a thickened ridge of tissue on the opposite, causing resonators to vibrate and produce sound. Two principal resonators are highlighted on this male's right forewing: the harp in purple and the mirror in turquoise. Flatwing males (right) have wings that are feminised and lack, or have severely reduced, resonators. They still make wing motions characteristic of singing despite the structural inability to produce sound ${ }^{93}$, but their silence protects them from the fly ${ }^{4}$. The flatwing phenotype segregates as a single-locus mutation on the X chromosome, and $100 \%$ of males from the population studied on Kauai now exhibit flatwing morphology. (Photo credits: N.W. Bailey) 
a

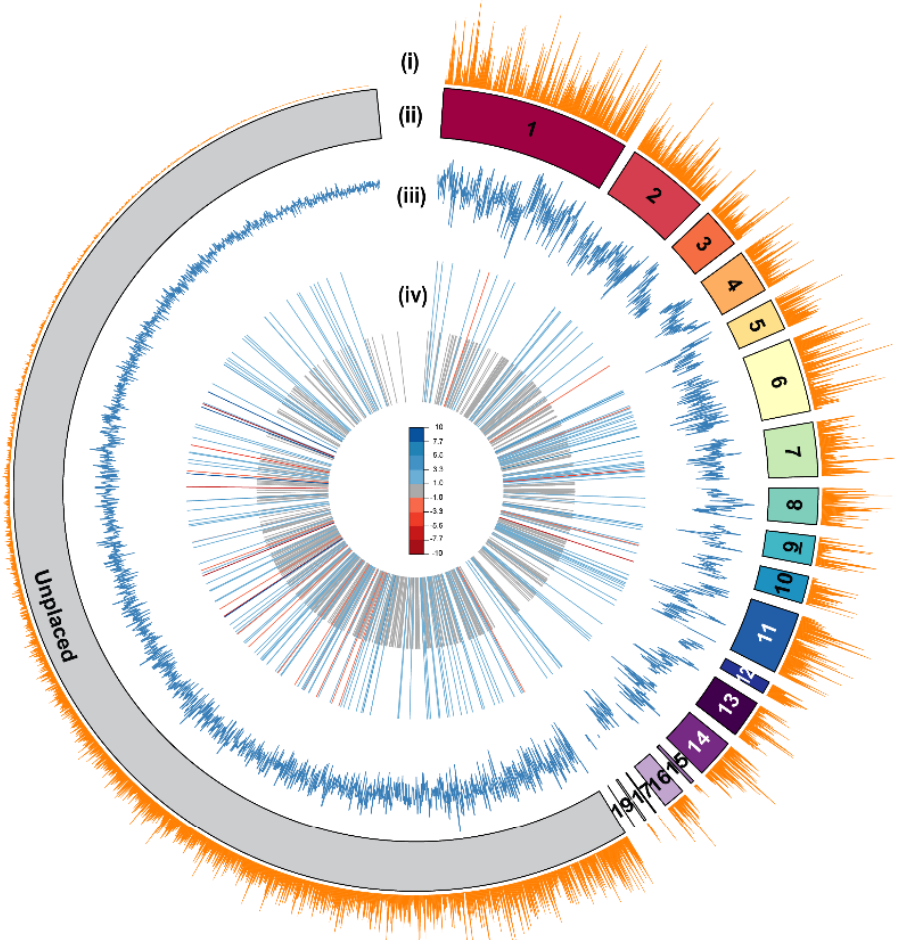

b

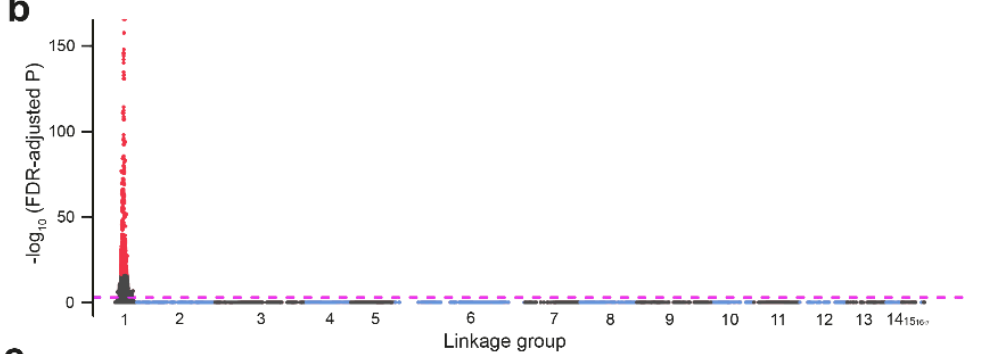

c

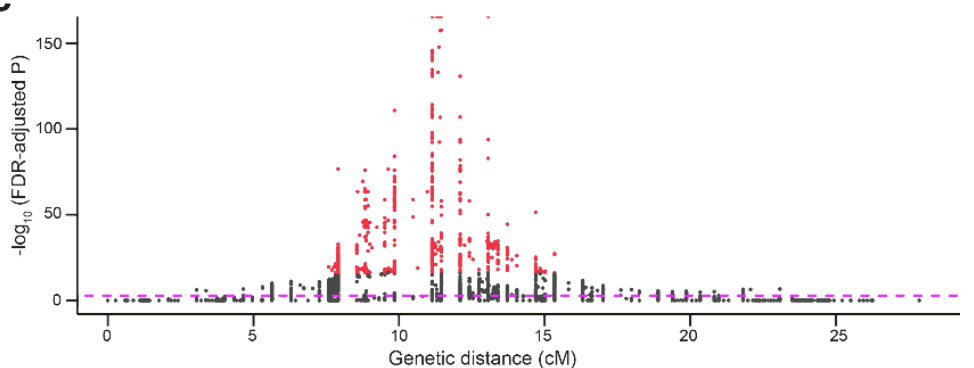

Fig. 2 | Teleogryllus oceanicus genome and regions associated with the flatwing phenotype. a, Circos plot providing an overview of the genome. Linkage groups (LGs) upon which genome scaffolds were anchored are shown in different colours, with unplaced scaffolds in gray. LG1 was identified as the $\mathrm{X}$ chromosome based on heterozygosity and coverage filters (see Main Text). Tracks (i): gene density, (ii): linkage group pseudomolecules, (iii): transposable element density, (iv): genes $\mathrm{DE}$ in the thoracic tissues of embryos homozygous for flatwing vs. normal-wing genotypes. Longer bars are DE genes for which $\log _{2} \mathrm{FC}$ $>1$ between genotypes, and short grey bars are all other DE genes. Colours indicate the magnitude of upregulation (red) versus downregulation (blue) in flatwing compared to normal-wing embryos. b, Genome-wide Manhattan plot of the flatwing QTL. Alternating shades of grey and blue indicate different LGs. The horizontal dashed line indicates an FDRcorrected significance threshold of $(P<0.001)$, and the top $1 \%$ most significant QTL markers are plotted in red. c, Enlarged plot for LG1 (X chromosome) showing the flatwingassociated peak. 
a

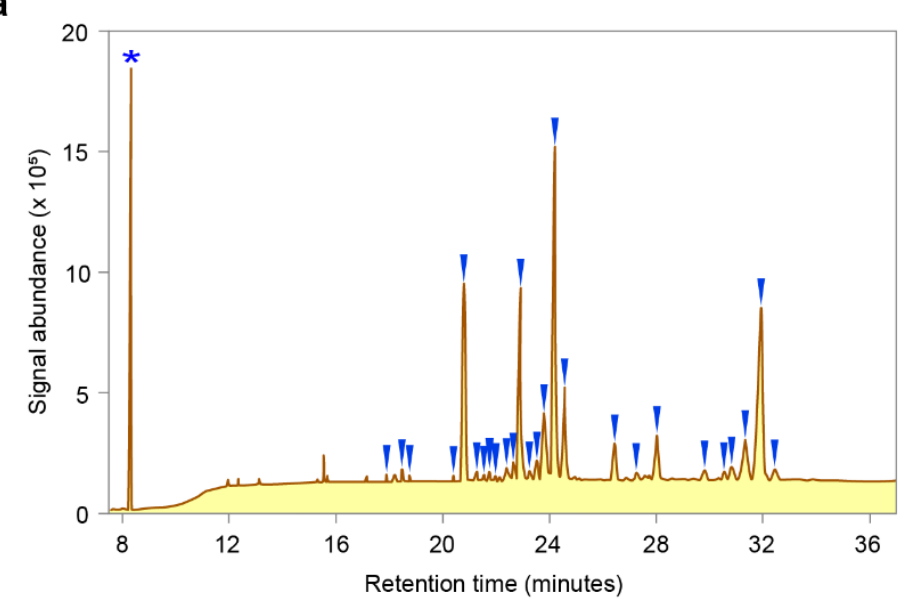

b

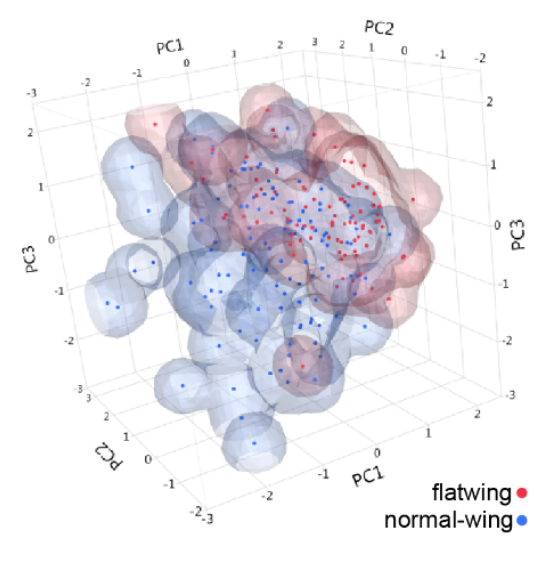

C
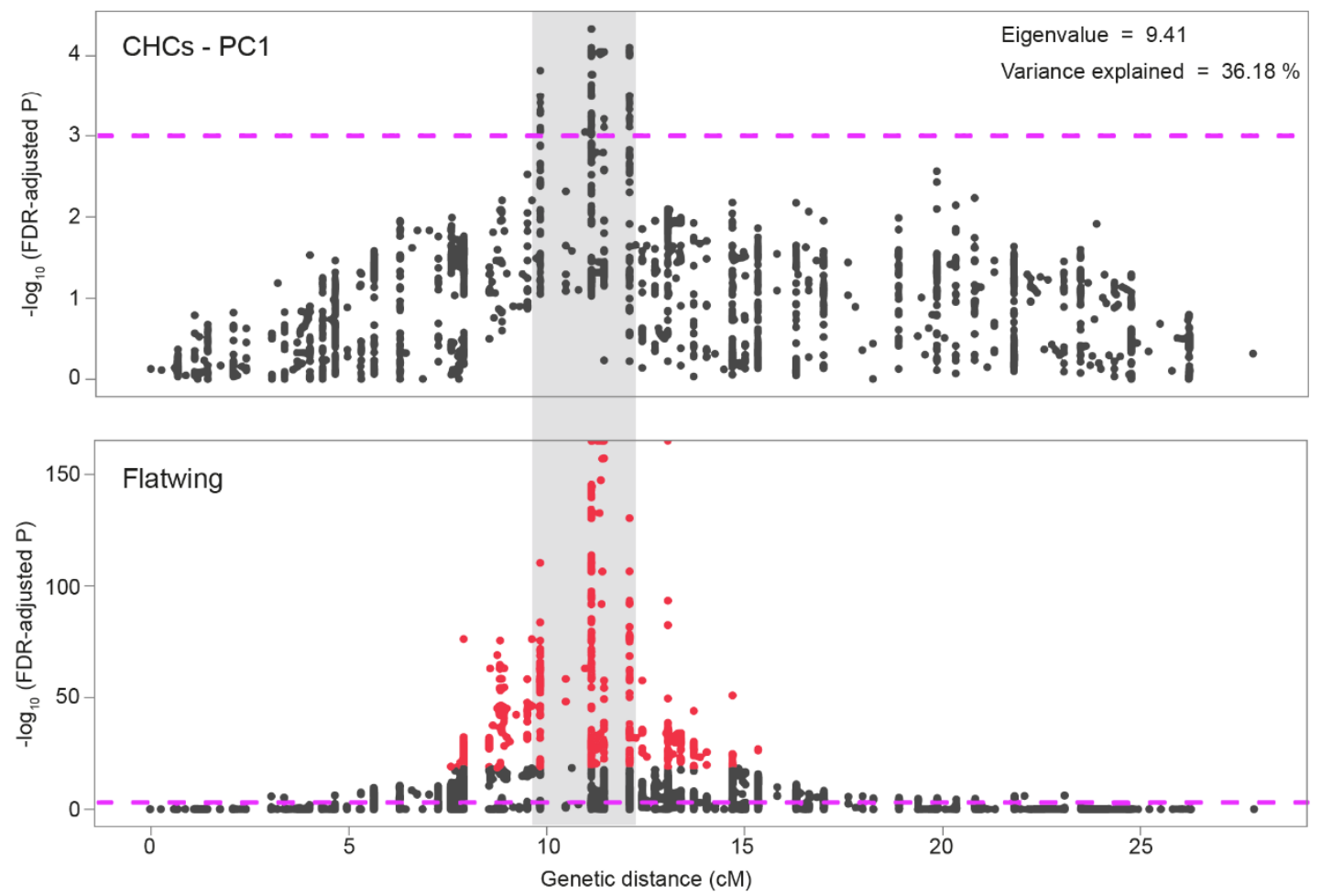

d
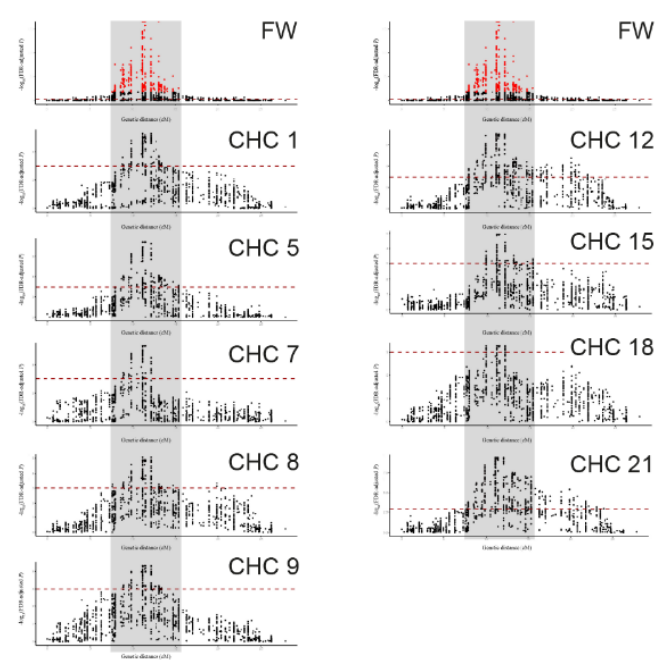

e

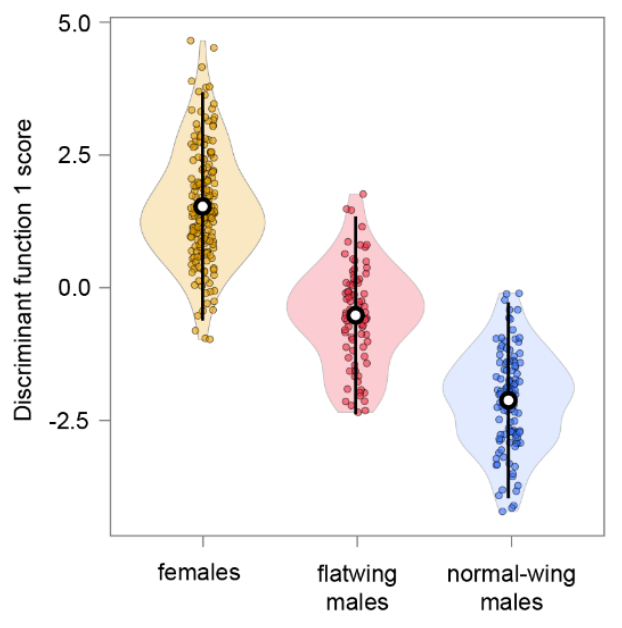


bioRxiv preprint doi: https://doi.org/10.1101/489526; this version posted December 9, 2018. The copyright holder for this preprint (which was not certified by peer review) is the author/funder, who has granted bioRxiv a license to display the preprint in perpetuity. It is made available under aCC-BY-NC-ND 4.0 International license.

Fig. 3 | Pleiotropic effects of flatwing cause feminisation of chemical sexual signals. a, Diagram of a T. oceanicus cuticular hydrocarbon (CHC) chromatogram, with the 26 measured peaks indicated by blue wedges. The asterisk indicates the internal standard (pentadecane). b, Space-filling scatterplot of the first three principal components describing male CHC profiles, illustrating differences between flatwing and normal-wing males (variance explained for PC1: 35.18\%, PC2: 10.14\%, PC3: 9.58\%). c, Comparison of QTL on the putative X chromosome for CHCs (top; first principal component mapped) and flatwing (bottom, same as Fig. 2C). Grey shading indicates the extent (in $\mathrm{cM}$ ) of the CHC peak, showing overlap with the flatwing QTL. Dashed lines indicate FDR-corrected significance of $p<0.001$, red points the top $1 \%$ significant flatwing QTL markers. Note the different y-axis scales. d, Univariate analyses revealed nine individual $\mathrm{CHC}$ components which also co-localised with flatwing. The original flatwing QTL is plotted at the top of each column. Grey shading spans the genetic region of colocalisation. Numbers refer to compounds indicated in $\mathbf{a}$, and dashed lines indicate an FDR-corrected significance threshold of $\mathrm{p}<0.001$. e, Discriminant function scores describing variation in CHC profiles among female, flatwing male and normal-wing male mapping individuals. Discriminant function 1 explained $78.8 \%$ of the variance in $\mathrm{CHC}$ profiles between groups. Means \pm 2 s.d. are indicated by open black-and-white circles and lines, respectively. 
Extended Data Table 1|T. oceanicus genome metrics

\begin{tabular}{|c|c|c|}
\hline $\begin{array}{l}\text { Maximum scaffold length } \\
\text { (bp) }\end{array}$ & \multicolumn{2}{|c|}{$2,637,780$} \\
\hline $\begin{array}{l}\text { Complete BUSCO } \\
\text { (Ref total }=1,066)\end{array}$ & \multicolumn{2}{|c|}{1,001} \\
\hline $\begin{array}{l}\text { \% complete BUSCO } \\
\text { (genome) }\end{array}$ & \multicolumn{2}{|c|}{$93.9 \%$} \\
\hline $\begin{array}{l}\text { \% complete BUSCO } \\
\text { (gene set) }{ }^{\mathrm{a}}\end{array}$ & \multicolumn{2}{|c|}{$83.2 \%$} \\
\hline Scaffold metrics & All contigs & Contigs $>1,000 \mathrm{bp}$ \\
\hline Total bases (gb) & $2,045,067,382$ & $2,044,651,628$ \\
\hline N50 (bp) & 62,615 & 62,685 \\
\hline Sequences in N50 & 6,139 & 6,136 \\
\hline GC content $(\%)$ & 40 & 40 \\
\hline Mean scaffold length (bp) & 10,335 & 10,355 \\
\hline Sequencing library yields & Read pairs & Yield (GB) \\
\hline Illumina TruSeq 180 & $277,076,641$ & 55.42 \\
\hline Illumina TruSeq 300 & $243,927,180$ & 48.79 \\
\hline Illumina TruSeq 600 & $238,275,727$ & 47.66 \\
\hline Illumina TruSeq Nano 350 & $70,959,741$ & 14.19 \\
\hline Illumina TruSeq Nano 550 & $63,415,263$ & 12.68 \\
\hline Illumina Nextera mate-pair & $229,431,023$ & 45.89 \\
\hline PacBio RSII & $5,771,779$ & 21.74 \\
\hline
\end{tabular}

${ }^{a}$ Final gene number identified in Extended Data Table 6 


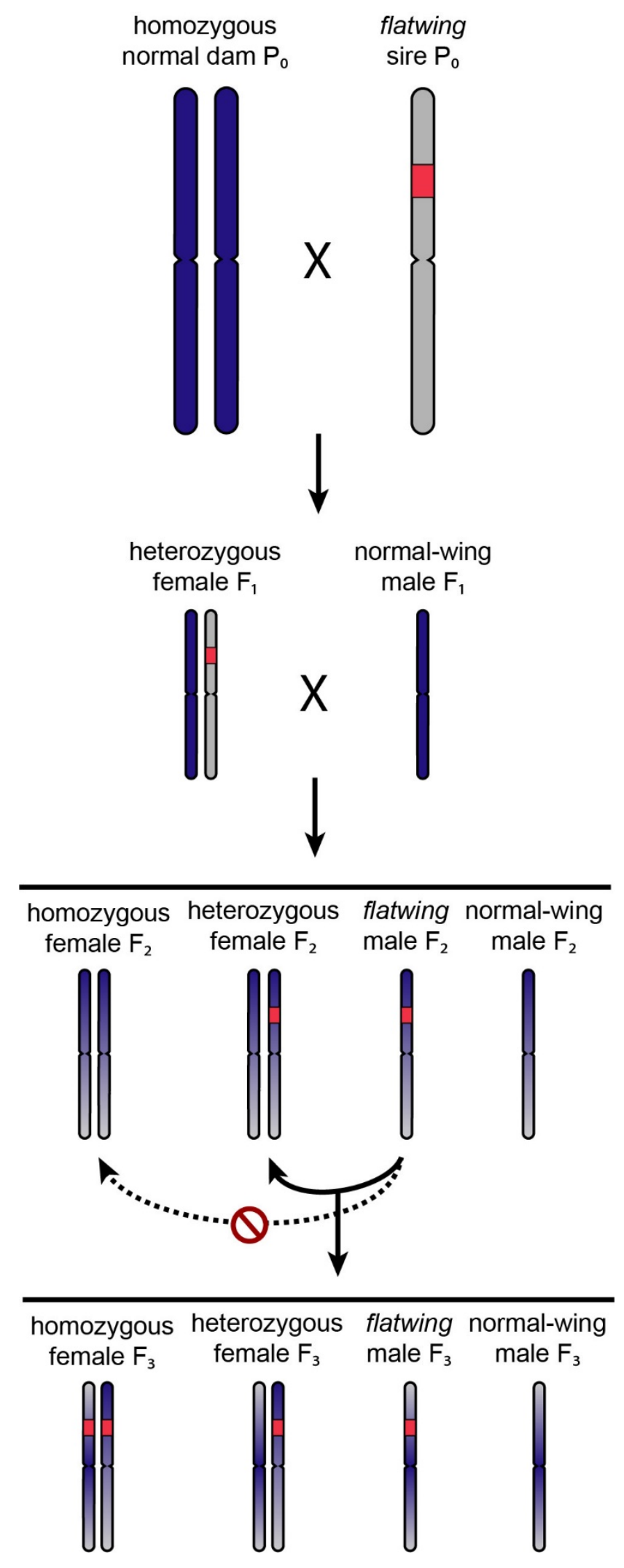

Extended Data Figure 1 | Cross design for linkage and QTL mapping. Flatwing segregates as a single-locus X-linked trait, so only $\mathrm{X}$ chromosomes are illustrated. A hypothetical flatwing locus is shaded in red. Females and males are XX/XO in T. oceanicus, so we performed three generations of crossing to enhance our ability to map flatwing. Homozygous normal-wing dams were obtained from a laboratory population of the same species originally derived from a population that has never contained flatwing (dark blue chromosomes). In the parental generation, these normal-wing dams were crossed to flatwing sires from Kauai (light grey chromosome, with hypothetical flatwing locus shaded in red). Dam genotypes were undetectable at generation $\mathrm{F}_{2}$ due to flatwing's sex-limited expression, so only full-sib crosses for which the flatwing male phenotype segregated in the subsequent $F_{3}$ generation were retained for phenotyping and QTL mapping (solid arrows). 


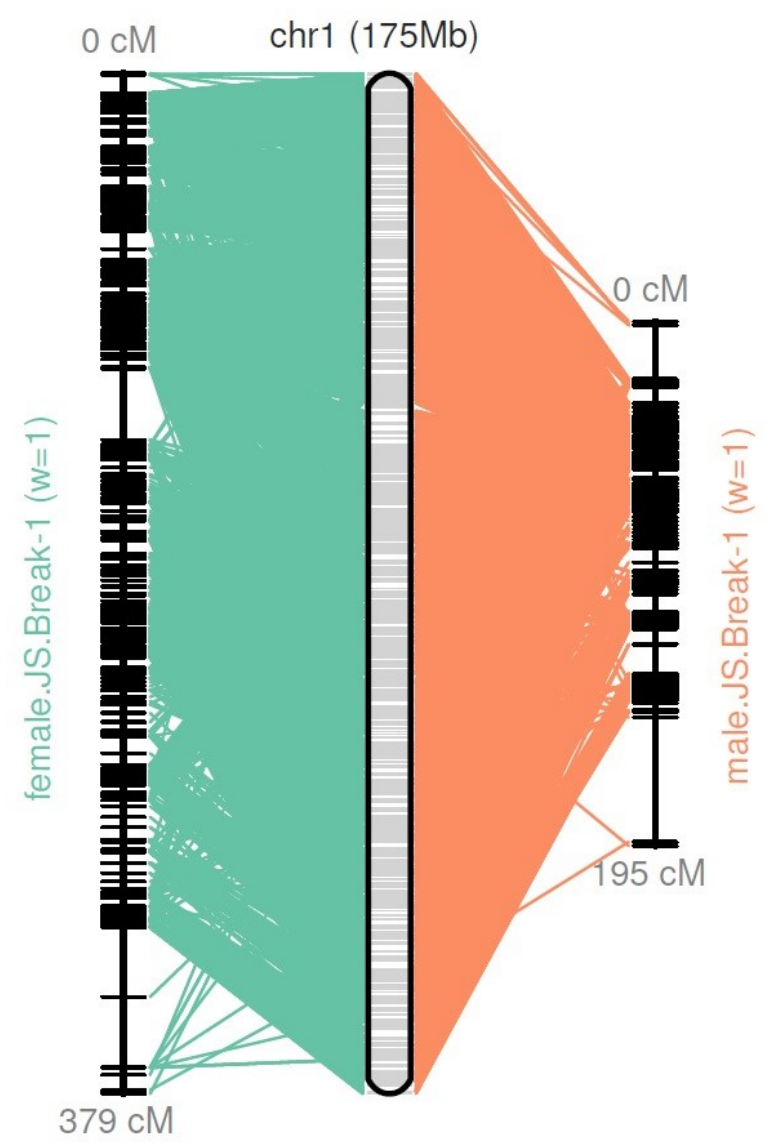

Extended Data Figure 2 | Reconstructed pseudomolecules for LG1 (putative X chromosome) using LOD5-supported markers. Female and male pseudomolecules are shown on the left and right, respectively, and lines connect the physical positions of markers on each pseudomolecule to map positions. 


\section{Extended Data Table $2 \mid$ List of chimeric scaffolds identified and corrected in the $T$. oceanicus genome}

\begin{tabular}{|c|c|c|c|c|}
\hline \multirow[t]{2}{*}{ Chime ric scaffold } & \multicolumn{2}{|c|}{ Coordinates } & \multirow[t]{2}{*}{ Corrected scaffold } & \multirow{2}{*}{$\begin{array}{c}\text { Linkage } \\
\text { group }\end{array}$} \\
\hline & Start & Stop & & \\
\hline Contig112_pilon & 1 & 280481 & Contig112_pilon.1 & LG13 \\
\hline Contig112_pilon & 285560 & 415702 & Contig112_pilon.2 & LG4 \\
\hline Contig115174_pilon & 1 & 4504 & Contig115174_pilon.1 & LG3 \\
\hline Contig115174_pilon & 4505 & 9682 & Contig115174_pilon.2 & LG5 \\
\hline Contig11656_pilon & 1 & 69510 & Contig11656_pilon.1 & LG3 \\
\hline Contig11656_pilon & 71880 & 189927 & Contig11656_pilon.2 & LG2 \\
\hline Contig122717_pilon & 1 & 791 & Contig122717_pilon.1 & LG12 \\
\hline Contig122717_pilon & 792 & 1738 & Contig122717_pilon. 2 & LG13 \\
\hline Contig12684_pilon & 1 & 94718 & Contig12684_pilon. 1 & LG14 \\
\hline Contig12684_pilon & 94719 & 233653 & Contig12684_pilon.2 & LG16 \\
\hline Contig157093_pilon & 1 & 21374 & Contig157093_pilon. 1 & LG1 \\
\hline Contig157093_pilon & 21375 & 29205 & Contig157093_pilon.2 & LG2 \\
\hline Contig16901_pilon & 1 & 14926 & Contig16901_pilon.1 & LG16 \\
\hline Contig16901_pilon & 18394 & 186701 & Contig16901_pilon.2 & LG11 \\
\hline Contig17374_pilon & 1 & 391141 & Contig17374_pilon.1 & LG11 \\
\hline Contig17374_pilon & 392712 & 614243 & Contig17374_pilon.2 & LG3 \\
\hline Contig19418_pilon & 1 & 216097 & Contig19418_pilon.1 & LG10 \\
\hline Contig19418_pilon & 220070 & 446236 & Contig19418_pilon.2 & LG12 \\
\hline Contig24478_pilon & 1 & 10308 & Contig24478_pilon.1 & LG19 \\
\hline Contig24478_pilon & 13057 & 232760 & Contig24478_pilon.2 & LG13 \\
\hline Contig25912_pilon & 1 & 178241 & Contig25912_pilon.1 & LG12 \\
\hline Contig25912_pilon & 180760 & 432977 & Contig25912_pilon.2 & LG11 \\
\hline Contig3004_pilon & 1 & 113166 & Contig3004_pilon.1 & LG10 \\
\hline Contig3004_pilon & 113846 & 201707 & Contig3004_pilon.2 & LG1 \\
\hline Contig30253_pilon & 1 & 75616 & Contig30253_pilon. 1 & LG6 \\
\hline Contig30253_pilon & 75924 & 107012 & Contig30253_pilon.2 & LG10 \\
\hline Contig30890_pilon & 1 & 42473 & Contig30890_pilon.1 & LG7 \\
\hline Contig30890_pilon & 42474 & 357127 & Contig30890_pilon.2 & LG4 \\
\hline Contig32501_pilon & 1 & 79400 & Contig32501_pilon.1 & LG8 \\
\hline
\end{tabular}


bioRxiv preprint doi: https://doi org/10.1101/489526: this version posted December 9 2018. The copyriaht holder for this preprint (which was not certified by peer review) is the author/funder, who has granted bioRxiv a license to display the preprint in perpetuity. It is made available under aCC-BY-NC-ND 4.0 International license.

\begin{tabular}{lrrll} 
Contig32501_pilon & 81158 & 104315 & Contig32501_pilon.2 & LG5 \\
\hline Contig34163_pilon & 1 & 276874 & Contig34163_pilon.1 & LG14 \\
\hline Contig34163_pilon & 278116 & 477845 & Contig34163_pilon.2 & LG8 \\
\hline Contig34793_pilon & 1 & 35174 & Contig34793_pilon.1 & LG13 \\
\hline Contig34793_pilon & 35175 & 226445 & Contig34793_pilon.2 & LG4 \\
\hline Contig37346_pilon & 1 & 181531 & Contig37346_pilon.1 & LG1 \\
\hline Contig37346_pilon & 185444 & 510953 & Contig37346_pilon.2 & LG5 \\
\hline Contig44873_pilon & 1 & 96939 & Contig44873_pilon.1 & LG3 \\
\hline Contig44873_pilon & 100500 & 540225 & Contig44873_pilon.2 & LG2 \\
\hline Contig53403_pilon & 1 & 162159 & Contig53403_pilon.1 & LG1 \\
\hline Contig53403_pilon & 163594 & 231179 & Contig53403_pilon.2 & LG12 \\
\hline Contig6264_pilon & 1 & 582129 & Contig6264_pilon.1 & LG1 \\
\hline Contig6264_pilon & 582130 & 671930 & Contig6264_pilon.2 & LG16 \\
\hline Contig6264_pilon & 675095 & 875693 & Contig6264_pilon.3 & LG1 \\
\hline Contig67999_pilon & 1 & 75111 & Contig67999_pilon.1 & LG8 \\
\hline Contig67999_pilon & 80918 & 230728 & Contig67999_pilon.2 & LG16 \\
\hline Contig7355_pilon & 1 & 31398 & Contig7355_pilon.1 & LG4 \\
\hline Contig7355_pilon & 31626 & 89218 & Contig7355_pilon.2 & LG7 \\
\hline & & & & \\
\hline
\end{tabular}


bioRxiv preprint doi: $h t t p s: / / d o i . o r g / 10.1101 / 489526$; this version posted December 9,2018 . The copyright holder for this preprint (which was not certified by peer review) is the author/funder, who has granted bioRxiv a license to display the preprint in perpetuity. It is made available under aCC-BY-NC-ND 4.0 International license.

Extended Data Table 3 | Summary statistics describing scaffold anchoring on T. oceanicus LOD5 linkage map markers

\begin{tabular}{lrrr}
\hline & Anchored & Oriented & Unplaced \\
\hline Markers (unique) & 104,713 & 88,665 & 741 \\
\hline Markers per Mb & 143.9 & 154.5 & 0.6 \\
Scaffolds & 8,169 & 5,997 & 189,726 \\
\hline Scaffolds with 1 marker & 686 & 0 & 187 \\
Scaffolds with 2 markers & 587 & 471 & 63 \\
\hline Scaffolds with 3 markers & 578 & 368 & 37 \\
Scaffolds with $>=4$ markers & 6,318 & 5,158 & 50 \\
\hline & $(35.6 \%)$ & $(28.1 \%)$ & $(64.4 \%)$ \\
\hline Total bases & & & $1,317,555,539$ \\
\hline
\end{tabular}



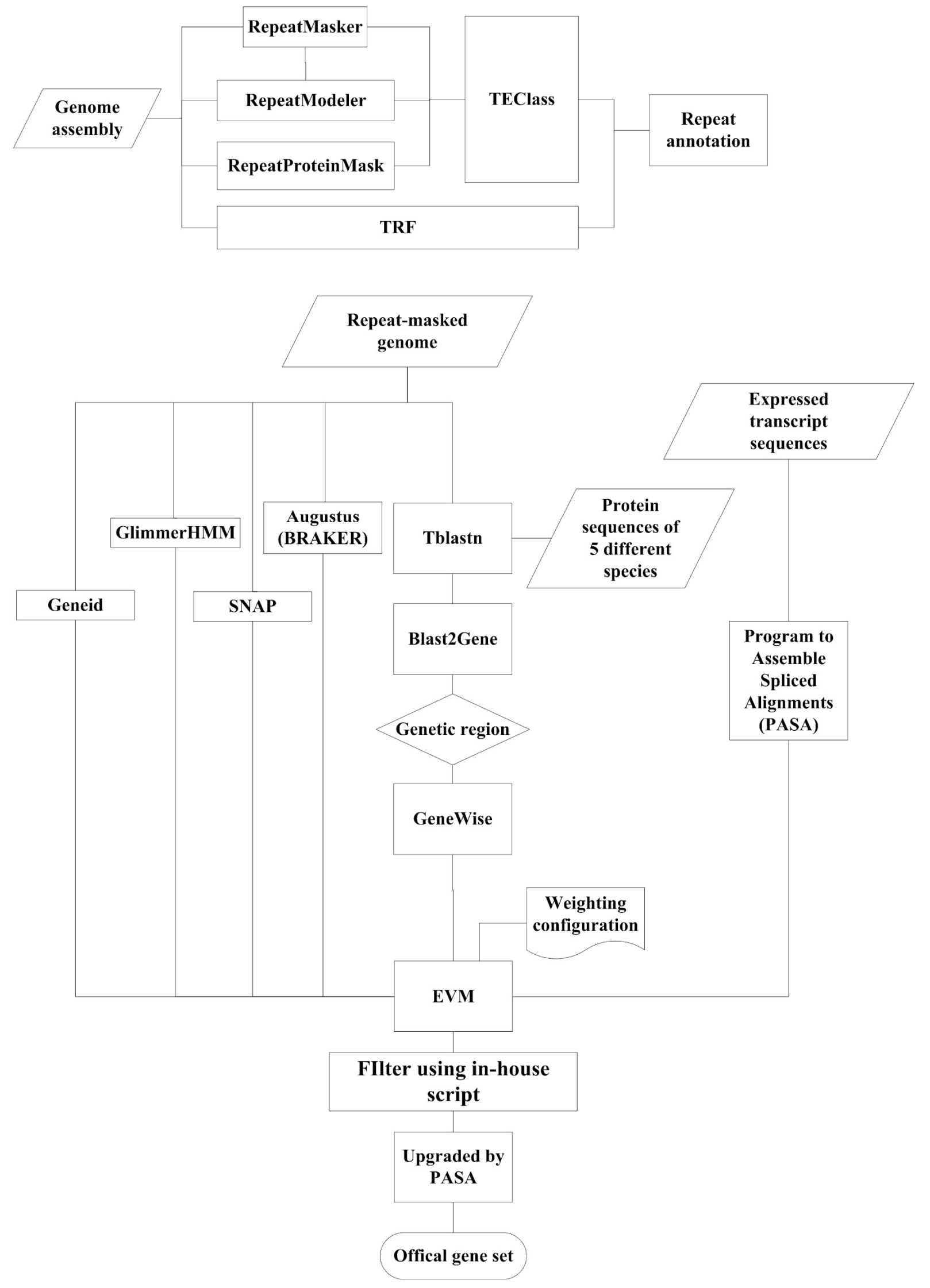

Extended Data Figure 3 | Workflow diagram of repeat annotation (top) and gene prediction (bottom) pipelines. Description of packages and parameters plus references are provided in the Methods section. 
bioRxiv preprint doi: https://doi.org/10.1101/489526; this version posted December 9, 2018. The copyright holder for this preprint (which was not certified by peer review) is the author/funder, who has granted bioRxiv a license to display the preprint in perpetuity. It is made available under aCC-BY-NC-ND 4.0 International license.

\section{Extended Data Table 4 | Functional annotation of T. oceanicus genes}

\begin{tabular}{lrrr}
\hline & & Number & $\begin{array}{c}\text { Proportion of } \\
\text { all genes (\%) }\end{array}$ \\
\hline Total & & 19,157 & - \\
\hline Annotated & InterPro & 12,318 & 64.3 \\
& Swissprot & 11,754 & 61.4 \\
& TrEMBL & 13,999 & 73.1 \\
& NR & 13,989 & 73.0 \\
\hline Unknown & Gene Ontology & 13,177 & 68.7 \\
\hline & KEGG & 9,579 & 50.0 \\
\hline
\end{tabular}




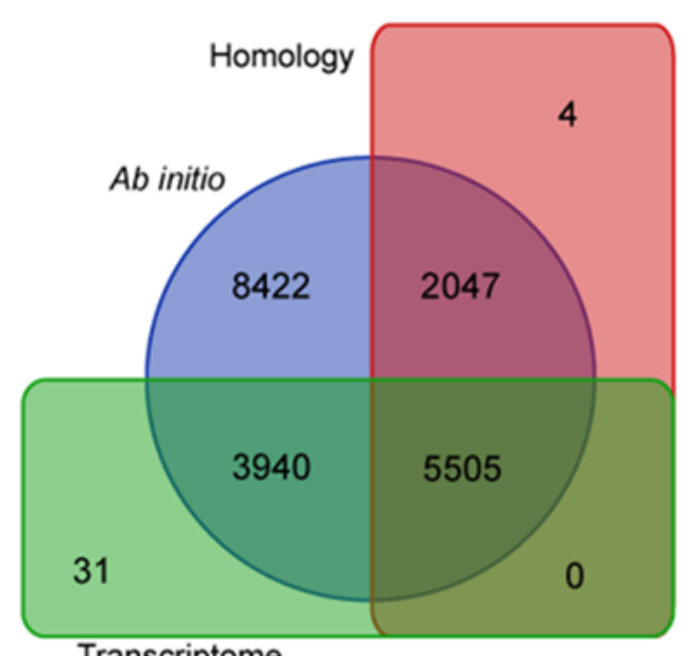

Transcriptome

Extended Data Figure 4 | Venn diagram of genes predicted for T. oceanicus using different methods. Counts refer to the gene set that was obtained prior to final upgrade and filtering using $\mathrm{PASA}^{71}$, so the total gene number above is slightly higher than the final gene set. A detailed description of each pipeline is presented in the Methods. 
Extended Data Table 5 | Distribution of repetitive elements for each scaffolded T. oceanicus linkage group

\begin{tabular}{|c|c|c|c|c|c|c|c|c|c|}
\hline $\begin{array}{l}\text { Linkage } \\
\text { group }\end{array}$ & $\begin{array}{l}\text { Transposable } \\
\text { elements (kb) }\end{array}$ & $\%$ & Rank $^{\mathbf{a}}$ & $\begin{array}{l}\text { Tandem } \\
\text { repeats }(k b)\end{array}$ & $\%$ & $\mathbf{R a n k}^{\mathbf{a}}$ & $\begin{array}{l}\text { Combined } \\
\text { (kb) }\end{array}$ & $\%$ & $\operatorname{Rank}^{\mathbf{a}}$ \\
\hline LG1 & 65992 & 38.6 & 8 & 1832 & 1.1 & 20 & 67823 & 39.7 & 11 \\
\hline LG2 & 26518 & 35.7 & 17 & 1123 & 1.5 & 14 & 27641 & 37.2 & 17 \\
\hline LG3 & 12908 & 36.3 & 14 & 572 & 1.6 & 13 & 13480 & 37.9 & 14 \\
\hline LG4 & 16514 & 42.0 & 2 & 848 & 2.2 & 4 & 17362 & 44.2 & 2 \\
\hline LG5 & 10253 & 36.2 & 15 & 500 & 1.8 & 11 & 10753 & 37.9 & 15 \\
\hline LG6 & 23187 & 35.0 & 18 & 925 & 1.4 & 17 & 24113 & 36.4 & 18 \\
\hline LG7 & 17533 & 36.3 & 13 & 936 & 1.9 & 8 & 18469 & 38.2 & 13 \\
\hline LG8 & 12770 & 38.8 & 6 & 617 & 1.9 & 7 & 13387 & 40.7 & 6 \\
\hline LG9 & 9952 & 38.2 & 9 & 659 & 2.5 & 2 & 10611 & 40.7 & 7 \\
\hline LG10 & 9359 & 38.2 & 10 & 545 & 2.2 & 5 & 9904 & 40.5 & 8 \\
\hline LG1 1 & 18920 & 34.1 & 19 & 804 & 1.5 & 15 & 19724 & 35.6 & 19 \\
\hline LG12 & 4850 & 42.7 & 1 & 297 & 2.6 & 1 & 5148 & 45.4 & 1 \\
\hline LG13 & 12684 & 37.4 & 12 & 624 & 1.8 & 10 & 13308 & 39.2 & 12 \\
\hline LG14 & 12629 & 36.2 & 16 & 483 & 1.4 & 16 & 13112 & 37.6 & 16 \\
\hline LG15 & 1298 & 41.7 & 3 & 53 & 1.7 & 12 & 1351 & 43.5 & 3 \\
\hline LG16 & 6292 & 31.5 & 20 & 243 & 1.2 & 19 & 6535 & 32.7 & 20 \\
\hline LG17 & 337 & 39.5 & 5 & 10 & 1.2 & 18 & 347 & 40.7 & 5 \\
\hline LG18 & 699 & 38.2 & 11 & 42 & 2.3 & 3 & 741 & 40.5 & 9 \\
\hline LG19 & 3 & 27.4 & 21 & 0 & 0.4 & 21 & 3 & 27.8 & 21 \\
\hline Unplaced & 526597 & 40.0 & 4 & 25416 & 1.9 & 6 & 552013 & 41.9 & 4 \\
\hline Total & 789295 & 38.6 & 7 & 36531 & 1.8 & 9 & 825826 & 40.4 & 10 \\
\hline
\end{tabular}

a Sorted by the proportion of repetitive elements in linkage groups, from most to fewest 


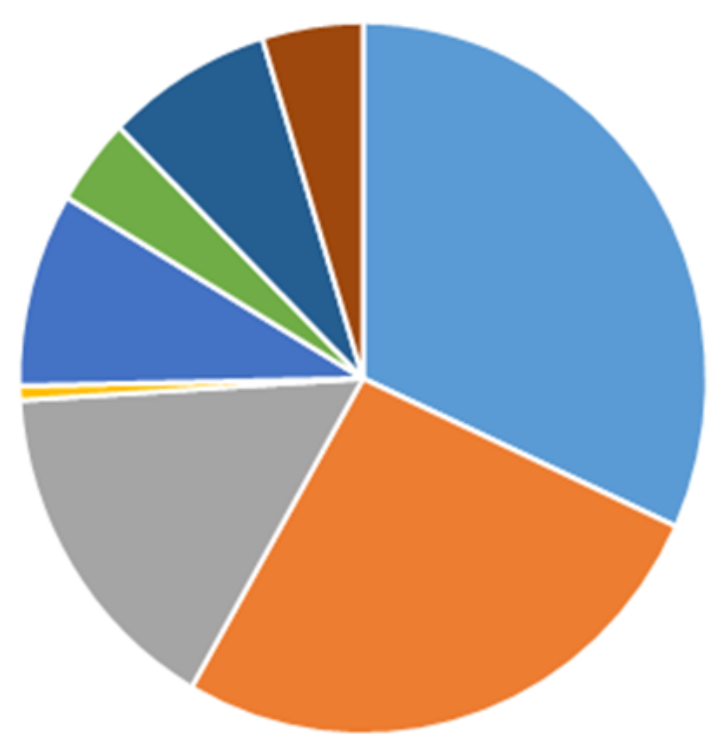

- DNA

- LINE

aTR

nonLTR

- Retro

SINE

- Simple repeat

- Unknown

Extended Data Figure 5 | Proportions of eight major categories of transposable elements detected in the $T$. oceanicus genome.

DNA $=$ DNA transposons

LTR $=$ long terminal repeats

LINE $=$ long interspersed nuclear elements

SINE $=$ short interspersed nuclear elements

Retro $=$ retrotransposon 
bioRxiv preprint doi: https://doi org/10.1101/489526: this version posted December 9,2018 The copyriaht holder for this preprint (which was not certified by peer review) is the author/funder, who has granted bioRxiv a license to display the preprint in perpetuity. It is made available under aCC-BY-NC-ND 4.0 International license.

\section{Extended Data Table 6 | Comparison of gene features among ten insect species}

\begin{tabular}{lccccccccc}
\hline Species & $\begin{array}{c}\text { Genome } \\
\text { assembly } \\
\text { size (Gb) }\end{array}$ & $\begin{array}{c}\text { Gene } \\
\text { number }\end{array}$ & $\begin{array}{c}\text { Single } \\
\text { exon } \\
\text { gene }\end{array}$ & $\%$ & $\begin{array}{c}\text { Average } \\
\text { gene } \\
\text { length }\end{array}$ & $\begin{array}{c}\text { Average } \\
\text { CDS } \\
\text { length } \\
\text { number }\end{array}$ & $\begin{array}{c}\text { Average } \\
\text { exon } \\
\text { number }\end{array}$ & $\begin{array}{c}\text { Average } \\
\text { exon } \\
\text { length } \\
\text { per } \\
\text { tbp) }\end{array}$ & $\begin{array}{c}\text { Ref. } \\
\text { transcript }\end{array}$
\end{tabular}

\begin{tabular}{|c|c|c|c|c|c|c|c|c|c|}
\hline \multicolumn{10}{|l|}{ Field cricket } \\
\hline $\begin{array}{l}\text { Teleogryllus } \\
\text { oceanicus }\end{array}$ & 2.0 & 19,157 & 1,266 & 6.6 & 12,232 & 1,184 & 6.2 & 395 & this study \\
\hline \multicolumn{10}{|l|}{ Migratory locust } \\
\hline Locusta migratoria & 6.5 & 17,307 & 3,079 & 17.8 & $54,341^{\mathrm{a}}$ & 1,160 & 5.8 & 201 & 62 \\
\hline \multicolumn{10}{|l|}{$\begin{array}{l}\text { American } \\
\text { Cockroach }\end{array}$} \\
\hline $\begin{array}{l}\text { Periplaneta } \\
\text { americana }\end{array}$ & 3.4 & 21,336 & 2,704 & 12.7 & $12,963^{b}$ & - & $4^{b}$ & $247^{b}$ & 94 \\
\hline
\end{tabular}

Fruit fly

Drosophila

melanogaster

$0.1 \quad 13,689$

$2,761 \quad 20.2$

4,261

1,621

$4.0 \quad 408 \quad 64 c$

Asian
long-horned beetle
Anoplophora
glabripennis

$0.7 \quad 16,200$

$1,194 \quad 7.4$

18,596

1,744

6.6

$265 \quad 65$

\section{Bed bug}

Cimex lectularius

$0.7 \quad 13,751$

$1,410 \quad 10.3$

29,076

1,846

10.2

26595

Brown

planthopper

Nilaparvata lugens

$1.1 \quad 21,442$

$2,179 \quad 10.2$

22,015

1,440

6.9

$289 \quad 66$

Dampwood termite

Zootermopsis

nevadensis

$0.5 \quad 15,129$

$370 \quad 2.4$

24,927

1,890

9.4

$365 \quad 96$

\section{Yellow fever}

mosquito

Aedes aegypti

$1.3 \quad 19,585$

$1,158 \quad 5.9 \quad 36,583$

2,144

6.4

$481 \quad 97$

\section{Asian Tiger}

mosquito

Aedes albopictus

$2.2 \quad 38,706$

2,305

6.0

25,506

1,950

5.3

$440 \quad 98$

${ }^{\text {a }}$ Originally reported average transcript length

b Originally reported medians

${ }^{c}$ Adapted from ${ }^{63}$ 
bioRxiv preprint doi: https://doi.org/10.1101/489526; this version posted December 9,2018 . The copyright holder for this preprint (which was not certified by peer review) is the author/funder, who has granted bioRxiv a license to display the preprint in perpetuity. It is made available under aCC-BY-NC-ND 4.0 International license.

Extended Data Table 7| Transposable element classification in T. oceanicus contrasted with three published genomes

\begin{tabular}{|c|c|c|c|c|c|c|c|c|}
\hline \multirow[b]{2}{*}{ Types } & \multicolumn{2}{|c|}{ T. oceanicus } & \multicolumn{2}{|c|}{ L. migratoria ${ }^{a}$} & \multicolumn{2}{|c|}{ D. melanogaster ${ }^{a}$} & \multicolumn{2}{|c|}{ H. sapiens ${ }^{a}$} \\
\hline & $\begin{array}{l}\text { Repeat size } \\
\text { (bp) }\end{array}$ & $\begin{array}{l}\% \text { of } \\
\text { genome }\end{array}$ & $\begin{array}{l}\text { Repeat size } \\
\text { (bp) }\end{array}$ & $\begin{array}{l}\% \text { of } \\
\text { genome }\end{array}$ & $\begin{array}{l}\text { Repeat size } \\
\text { (bp) }\end{array}$ & $\begin{array}{l}\% \text { of } \\
\text { genome }\end{array}$ & Repeat size (bp) & $\begin{array}{c}\% \text { of } \\
\text { genome }\end{array}$ \\
\hline DNA & 259181458 & 12.7 & $1,480,538,225$ & 22.7 & $4,849,763$ & 2.9 & $99,797,428$ & 3.2 \\
\hline LINE & 215705991 & 10.5 & $1,332,720,207$ & 20.4 & $12,119,904$ & 7.2 & $637,919,432$ & 20.3 \\
\hline LTR & 127951980 & 6.3 & $508,675,263$ & 7.8 & $21,849,378$ & 13.0 & $267,738,295$ & 8.5 \\
\hline nonLTR & 5233875 & 0.3 & $63,892,419$ & 1.0 & - & - & - & - \\
\hline Retro & 71828043 & 3.5 & $153,548,453$ & 2.4 & - & - & - & - \\
\hline SINE & 32344731 & 1.6 & $141,176,698$ & 2.2 & 52,841 & 0.0 & $397,225,496$ & 12.7 \\
\hline Simple repeat & 63555524 & 3.1 & $13,026,240$ & 0.2 & 2,733 & 0.0 & $26,240,511$ & 0.8 \\
\hline Unknown & 38615245 & 1.9 & $406,097,360$ & 6.2 & $11,211,970$ & 6.6 & $1,298,163$ & 0.0 \\
\hline Total & 789295269 & 38.6 & $3,840,808,141$ & 58.9 & $50,785,143$ & 30.0 & $1,434,373,137$ & 46.0 \\
\hline
\end{tabular}

DNA $=$ DNA transposons

$\mathrm{LTR}=$ long terminal repeats

LINE $=$ long interspersed nuclear elements

$\mathrm{SINE}=$ short interspersed nuclear elements

Retro $=$ retrotransposon

a Data from ${ }^{61}$ 
bioRxiv preprint doi: https://doi.org/10.1101/489526; this version posted December 9, 2018. The copyright holder for this preprint (which was not certified by peer review) is the author/funder, who has granted bioRxiv a license to display the preprint in perpetuity. It is made available under aCC-BY-NC-ND 4.0 International license.

Extended Data Table 8 | Thoracic gene expression variation between embryonic crickets carrying

flatwing vs. normal-wing genotypes

\begin{tabular}{lr}
\hline Total number of genes passing expression filtering & 10,961 \\
Total DE genes & 830 \\
Up-regulated in flatwing & 328 \\
Down-regulated in flatwing & 502 \\
DE genes with log IC $_{\mathbf{P}} \mathbf{1}$ & 204 \\
Up-regulated in flatwing & 25 \\
Down-regulated in flatwing & 179 \\
\hline
\end{tabular}




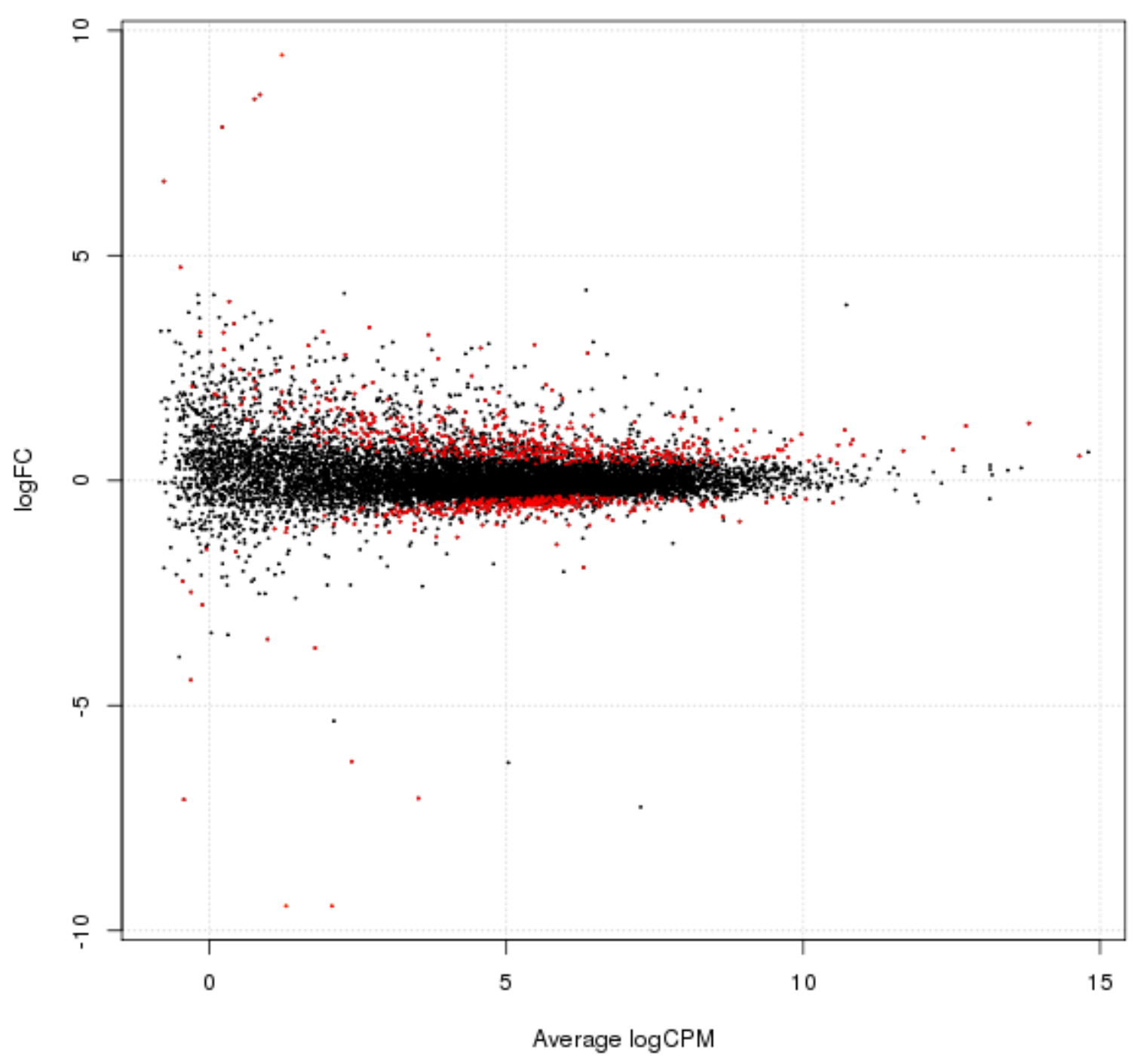

Extended Data Figure 6 | MA plot of thoracic genes DE between T. oceanicus embryos that were homozygous for flatwing vs. normal-wing. Red points indicate significantly differentially-expressed genes after filtering (see Methods), with positive values on the y-axis indicating genes downregulated in flatwing samples compared to normal-wing samples, and negative values indicating genes that are upregulated in flatwing samples. Log scales are base 2. 


\section{Extended Data Table 9 | GO analysis of thoracic DEGs between embryos carrying flatwing vs. normal-wing genotypes}

\begin{tabular}{|c|c|c|c|c|}
\hline GO & Type & Function & $\begin{array}{l}\text { No. of } \\
\text { DEGs }\end{array}$ & $P$-adj. \\
\hline GO:0003824 & molecular_function & catalytic activity & 216 & 0.006 \\
\hline GO:0016787 & molecular_function & hydrolase activity & 80 & 0.027 \\
\hline GO:0044087 & biological_process & $\begin{array}{l}\text { regulation of cellular component } \\
\text { biogenesis }\end{array}$ & 20 & 0.004 \\
\hline GO:0051493 & biological_process & $\begin{array}{l}\text { regulation of cytoskeleton } \\
\text { organization }\end{array}$ & 12 & 0.023 \\
\hline GO:0090066 & biological_process & $\begin{array}{l}\text { regulation of anatomical structure } \\
\text { size }\end{array}$ & 12 & 0.009 \\
\hline GO:0097435 & biological_process & supramolecular fiber organization & 12 & 0.023 \\
\hline GO:0032535 & biological_process & regulation of cellular component size & 11 & 0.004 \\
\hline GO:0032956 & biological_process & $\begin{array}{l}\text { regulation of actin cytoskeleton } \\
\text { organization }\end{array}$ & 11 & 0.001 \\
\hline GO:0032970 & biological_process & $\begin{array}{l}\text { regulation of actin filament-based } \\
\text { process }\end{array}$ & 11 & 0.001 \\
\hline GO:1902903 & biological_process & $\begin{array}{l}\text { regulation of supramolecular fiber } \\
\text { organization }\end{array}$ & 11 & 0.002 \\
\hline GO:0043254 & biological_process & $\begin{array}{l}\text { regulation of protein complex } \\
\text { assembly }\end{array}$ & 10 & 0.035 \\
\hline GO:0110053 & biological_process & $\begin{array}{l}\text { regulation of actin filament } \\
\text { organization }\end{array}$ & 10 & 0.001 \\
\hline GO:0008064 & biological_process & $\begin{array}{l}\text { regulation of actin polymerization or } \\
\text { depolymerization }\end{array}$ & 8 & 0.006 \\
\hline GO:0030832 & biological_process & regulation of actin filament length & 8 & 0.006 \\
\hline GO:0030833 & biological_process & $\begin{array}{l}\text { regulation of actin filament } \\
\text { polymerization }\end{array}$ & 8 & 0.006 \\
\hline GO:0032271 & biological_process & regulation of protein polymerization & 8 & 0.015 \\
\hline GO:0015630 & cellular_component & microtubule cytoskeleton & 6 & 0.001 \\
\hline GO:0005248 & molecular_function & voltage-gated sodium channel activity & 5 & 0.004 \\
\hline GO:0010927 & biological_process & $\begin{array}{l}\text { cellular component assembly } \\
\text { involved in morphogenesis }\end{array}$ & 5 & 0.010 \\
\hline GO:0034706 & cellular_component & sodium channel complex & 4 & 0.007 \\
\hline
\end{tabular}




\section{Extended Data Table 10 | KEGG pathway enrichment of thoracic DEGs between embryos carrying flatwing vs. normal-wing genotypes}

\begin{tabular}{|c|c|c|c|c|}
\hline ID $^{\mathbf{a}}$ & Pathway & $\begin{array}{l}\text { No. of } \\
\text { genes }\end{array}$ & $P$-value & $P$-adj.c \\
\hline map04520 & Adherens junction & 13 & $<0.001$ & 0.025 \\
\hline map03030 & DNA replication & 9 & 0.001 & 0.264 \\
\hline map05100 & Bacterial invasion of epithelial cells & 9 & 0.007 & 0.408 \\
\hline map05130 & Pathogenic Escherichia coli infection & 9 & 0.005 & 0.408 \\
\hline map01100 & Metabolic pathways & 59 & 0.013 & 0.552 \\
\hline map04960 & Aldosterone-regulated sodium reabsorption & 5 & 0.012 & 0.552 \\
\hline map04064 & NF-kappa B signaling pathway & 5 & 0.021 & 0.687 \\
\hline map04711 & Circadian rhythm - fly & 3 & 0.024 & 0.715 \\
\hline map00230 & Purine metabolism & 18 & 0.038 & 0.744 \\
\hline $\operatorname{map} 03430$ & Mismatch repair & 5 & 0.035 & 0.744 \\
\hline map04111 & Cell cycle - yeast & 10 & 0.033 & 0.744 \\
\hline map04115 & p53 signaling pathway & 6 & 0.037 & 0.744 \\
\hline map04670 & Leukocyte transendothelial migration & 7 & 0.037 & 0.744 \\
\hline map04927 & Cortisol synthesis and secretion & 5 & 0.031 & 0.744 \\
\hline map03410 & Base excision repair & 5 & 0.044 & 0.765 \\
\hline map04022 & cGMP-PKG signaling pathway & 11 & 0.048 & 0.765 \\
\hline map04530 & Tight junction & 12 & 0.043 & 0.765 \\
\hline
\end{tabular}

a Pathways describing human disease not shown

${ }^{b}$ Fisher's exact test

c FDR-corrected 


\section{Extended Data Table 11 | Top candidate genes associated with flatwing}

\begin{tabular}{|c|c|c|c|c|c|c|}
\hline \multicolumn{3}{|l|}{ Coordinates } & \multirow[b]{2}{*}{ Gene ID } & \multirow{2}{*}{\multicolumn{2}{|c|}{ Description $^{a}$}} & \multirow[b]{2}{*}{ Source ${ }^{b}$} \\
\hline Scaffold & Start & Stop & & & & \\
\hline Contig10220_pilon & 78887 & 163134 & TOT000182.1 & YGD6 & $\begin{array}{l}\text { Zinc-type alcohol dehydrogenase-like protein } \\
\text { C1773.06c }\end{array}$ & Top $1 \%$ \\
\hline Contig11287_pilon & 199864 & 215783 & ТОТ001075.1 & HNF4 & Transcription factor HNF-4 homolog & Top $1 \%$ \\
\hline Contig12423_pilon & 12805 & 162659 & ТОТ001854.1 & OSM3 & Osmotic avoidance abnormal protein 3 & Top $1 \%$ \\
\hline Contig12752_pilon & 14326 & 68612 & TOT002129.1 & ROR1 & $\begin{array}{l}\text { Inactive tyrosine-protein kinase transmembrane } \\
\text { receptor ROR1 }\end{array}$ & Top $1 \%$ \\
\hline Contig12919_pilon & 275064 & 329308 & TOT002239.1 & CLOCK & Circadian locomotor output cycles protein kaput & $\begin{array}{l}\text { Top } 1 \% \\
\text { DEG }\end{array}$ \\
\hline Contig13810_pilon & 43734 & 77412 & ТОТ002877.1 & CRTAP & Cartilage-associated protein & Top $1 \%$ \\
\hline Contig140_pilon & 14528 & 100227 & ТОТ003072.1 & PP4R1 & $\begin{array}{l}\text { Serine/threonine-protein phosphatase } 4 \\
\text { regulatory subunit } 1\end{array}$ & Top $1 \%$ \\
\hline Contig17198_pilon & 217974 & 328434 & ТОТ004721.1 & SCN60 & Sodium channel protein $60 \mathrm{E}$ & Top 1\% \\
\hline Contig17198_pilon & 398116 & 526355 & ТОТ004722.1 & SCN60 & Sodium channel protein $60 \mathrm{E}$ & Top $1 \%$ \\
\hline Contig17528_pilon & 151965 & 161397 & ТОТ 004867.1 & OBSTE & Protein obstructor-E & $\begin{array}{l}\text { Kauai } \\
\text { DEG }\end{array}$ \\
\hline Contig17791_pilon & 294998 & 303418 & ТОТ005017.1 & PKRA & Protein krasavietz & $\begin{array}{l}\text { DEG } \\
\text { QTL }\end{array}$ \\
\hline Contig18506_pilon & 5030 & 106086 & TOT005335.1 & STRN3 & Striatin-3 & Top $1 \%$ \\
\hline Contig20777_pilon & 197732 & 433721 & ТОТ006213.1 & COLL & Transcription factor collier & $\begin{array}{l}\text { Top } 1 \% \\
\text { BSA }\end{array}$ \\
\hline Contig23358_pilon & 266813 & 357642 & ТОТ006927.1 & E78C & Ecdysone-induced protein 78C (Eip78C) & Top $1 \%$ \\
\hline Contig23647_pilon & 61437 & 289082 & ТОТ006991.1 & RAVR1 & Ribonucleoprotein PTB-binding 1 & Top $1 \%$ \\
\hline Contig24519_pilon & 221508 & 332371 & ТОТ 007217.1 & $\begin{array}{l}\text { A0A167 } \\
\text { WTZ1 }\end{array}$ & Endo-1,3(4)-beta-glucanase & Top $1 \%$ \\
\hline Contig24519_pilon & 569981 & 635619 & ТОТ007221.1 & SEPIA & Pyrimidodiazepine synthase & Top $1 \%$ \\
\hline Contig30320_pilon & 33122 & 79411 & ТОТ008755.1 & PTPC1 & $\begin{array}{l}\text { Protein tyrosine phosphatase domain-containing } \\
\text { protein } 1\end{array}$ & Top $1 \%$ \\
\hline Contig3077_pilon & 487713 & 492969 & ТОТ008894.1 & REXO4 & RNA exonuclease 4 & Top $1 \%$ \\
\hline Contig31374_pilon & 378769 & 413960 & ТОТ009065.1 & CPT2 & $\begin{array}{l}\text { Carnitine O-palmitoyltransferase } 2 \text {, } \\
\text { mitochondrial }\end{array}$ & Top $1 \%$ \\
\hline Contig31374_pilon & 461061 & 489320 & ТОТ009067.1 & FRM4B & FERM domain-containing protein 4B & Top $1 \%$ \\
\hline Contig32190_pilon & 94344 & 248306 & ТОТ009274.1 & RN207 & RING finger protein 207 & Top $1 \%$ \\
\hline Contig35402_pilon & 14084 & 125884 & ТОТ010060.1 & ABCG1 & ATP-binding cassette sub-family G member 1 & Top $1 \%$ \\
\hline Contig37346_pilon.1 & 133394 & 180067 & ТОТ010542.1 & SCYL1 & N-terminal kinase-like protein & Top $1 \%$ \\
\hline Contig40107_pilon & 150347 & 172207 & ТОТ011176.1 & THUM3 & THUMP domain-containing protein 3 & $\begin{array}{l}\text { DEG, } \\
\text { QTL }\end{array}$ \\
\hline Contig4430_pilon & 60074 & 108676 & ТОT012009.1 & LAR & Tyrosine-protein phosphatase Lar & Top $1 \%$ \\
\hline Contig4497_pilon & 323 & 114981 & ТОТ012126.1 & MYO5A & Unconventional myosin- $\mathrm{Va}$ & Top $1 \%$ \\
\hline Contig48084_pilon & 4534 & 15580 & ТОТ012711.1 & KPEL & Serine/threonine-protein kinase pelle & Top $1 \%$ \\
\hline Contig48322_pilon & 73569 & 78934 & ТОТ012764.1 & CAH10 & Carbonic anhydrase-related protein 10 & Top $1 \%$ \\
\hline
\end{tabular}


bioRxiv preprint doi: https://doi org/10.1101/489526; this version posted December 9,2018 . The copyright holder for this preprint (which was not certified by peer review) is the author/funder, who has granted bioRxiv a license to display the preprint in perpetuity. It is made available under aCC-BY-NC-ND 4.0 International license.

\begin{tabular}{|c|c|c|c|c|c|c|}
\hline Contig52923_pilon & 4299 & 134158 & ТОТ013504.1 & RENT2 & Regulator of nonsense transcripts 2 & $\begin{array}{l}\text { Top 1\% } \\
\text { DEG }\end{array}$ \\
\hline Contig52923_pilon & 172817 & 234071 & ТОТ013505.1 & NBL1 & Neuroblastoma suppressor of tumorigenicity 1 & Top $1 \%$ \\
\hline Contig53931_pilon & 135337 & 200203 & ТОТ013689.1 & TADBP & TAR DNA-binding protein 43 & Top $1 \%$ \\
\hline Contig55532_pilon & 2641 & 6823 & ТОТ013967.1 & SOSSC & SOSSC_BOVIN & Top $1 \%$ \\
\hline Contig5817_pilon & 13001 & 94458 & ТОТО14395.1 & $\begin{array}{l}\text { A0A1B6 } \\
\text { LWD6 }\end{array}$ & Uncharacterized protein & Top $1 \%$ \\
\hline Contig6025_pilon & 181847 & 338853 & ТОТ014693.1 & PAX6 & Paired box protein Pax-6 & Top $1 \%$ \\
\hline Contig6181_pilon & 7490 & 15461 & ТОТ014894.1 & MYCT & Proton myo-inositol cotransporter & Top $1 \%$ \\
\hline Contig6371_pilon & 72321 & 126646 & ТОТ015146.5 & GOGA4 & Golgin subfamily A member 4 & Top $1 \%$ \\
\hline Contig6636_pilon & 248427 & 279756 & ТОТ015511.1 & $\begin{array}{l}\text { A0A067 } \\
\text { RPQ2 }\end{array}$ & LRR domain-containing protein & Top $1 \%$ \\
\hline Contig6636_pilon & 332473 & 344815 & ТОТ015512.1 & $\begin{array}{l}\text { IPR0110 } \\
11\end{array}$ & Uncharacterized protein & Top $1 \%$ \\
\hline Contig66512_pilon & 19778 & 188429 & ТОТ015537.1 & LASP 1 & LIM and SH3 domain protein F42H10.3 & $\begin{array}{l}\text { Top } 1 \% \\
\text { DEG }\end{array}$ \\
\hline Contig6932_pilon & 94582 & 114944 & ТОТ015868.1 & $\mathrm{ABCB} 8$ & $\begin{array}{l}\text { ATP-binding cassette sub-family B member } 8 \text {, } \\
\text { mitochondrial }\end{array}$ & Top $1 \%$ \\
\hline Contig6932_pilon & 132941 & 150338 & ТОТ015869.1 & APMAP & Adipocyte plasma membrane-associated protein & Top $1 \%$ \\
\hline Contig7020_pilon & 57223 & 96643 & ТОТ015999.1 & SPS1 & Selenide, water dikinase & Top $1 \%$ \\
\hline Contig7210_pilon & 172512 & 326460 & ТОТ016305.1 & MYO & myoglianin & Top $1 \%$ \\
\hline Contig7490_pilon & 12720 & 16839 & ТОТ016652.1 & GCN5 & Histone acetyltransferase GCN5 & Top $1 \%$ \\
\hline Contig8190_pilon & 192630 & 256540 & ТОТ017431.1 & AT 133 & Probable cation-transporting ATPase $13 \mathrm{~A} 3$ & Top $1 \%$ \\
\hline Contig82459_pilon & 106133 & 176987 & ТОТ017512.1 & UNC89 & Muscle M-line assembly protein unc- 89 & $\begin{array}{l}\text { DEG } \\
\text { QTL }\end{array}$ \\
\hline Contig83863_pilon & 1777 & 51856 & ТОТ017662.1 & $\begin{array}{l}\text { A0A017 } \\
\text { RSC4 }\end{array}$ & Uncharacterized protein & Top $1 \%$ \\
\hline Contig92683_pilon & 43257 & 76189 & ТОТ018508.1 & $\begin{array}{l}\text { A0A0T6 } \\
\text { B8G7 }\end{array}$ & Uncharacterized protein & Top $1 \%$ \\
\hline Contig33215_pilon & 67326 & 419738 & ТОТ009518.1 & PLXA4 & Plexin-A4 & $\begin{array}{l}\text { QTL } \\
\text { BSA }\end{array}$ \\
\hline Contig43580_pilon & 106377 & 137341 & ТОТ011864.1 & RNF41 & E3 ubiquitin-protein ligase NRDP1 & $\begin{array}{l}\text { QTL } \\
\text { BSA }\end{array}$ \\
\hline
\end{tabular}

${ }^{\text {a }}$ Functional descriptions and references provided in Main Text

${ }^{b}$ The criterion for inclusion as a top candidate was that a gene had to receive support for association with the flatwing phenotype from at least two of the following four sources:

$\mathrm{QTL}=$ portion of the gene was located within a $1 \mathrm{~kb}$ flanking region of a significantlyassociated (FDR-corrected) marker in the flatwing QTL analysis

Top $1 \%=$ portion of the gene was located within a $1 \mathrm{~kb}$ flanking region of a SNP in the top $1 \%$ of significantly-associated markers in the flatwing QTL analysis (Top $1 \%$ candidates automatically received "QTL" support)

$\mathrm{BSA}=$ portion of the gene was located within a $1 \mathrm{~kb}$ flanking region of a significantlyassociated marker from the previously-published bulked segregant analysis of Kauai flatwing males ${ }^{7}$ which was also anchored to LG1

$\mathrm{DEG}=$ gene was significantly differentially expressed between pure-breeding normal-wing genotypes and flatwing genotypes, in embryonic thoracic tissue (track iv of Fig. 2a in Main Text) 


\section{Extended Data Table 12 | GO analysis of candidate flatwing-associated genes (CGs)}

\begin{tabular}{lllll}
\hline GO & Type & Function & $\begin{array}{l}\text { No.of } \\
\text { CGs }\end{array}$ & $\begin{array}{l}\boldsymbol{P} \text {-adj. } \\
(\boldsymbol{2} \text { test })\end{array}$ \\
\hline GO:0010720 & biological_process & positive regulation of cell development & 3 & $<0.001$ \\
\hline GO:0045597 & biological_process & positive regulation of cell differentiation & 3 & 0.002 \\
\hline GO:0060284 & biological_process & regulation of cell development & 3 & 0.042 \\
\hline GO:0003707 & molecular_function & steroid hormone receptor activity & 2 & $<0.001$ \\
\hline GO:0009755 & biological_process & hormone-mediated signaling pathway & 2 & 0.006 \\
\hline GO:0030545 & molecular_function & receptor regulator activity & 2 & 0.035 \\
\hline GO:0043401 & biological_process & $\begin{array}{l}\text { steroid hormone mediated signaling } \\
\text { pathway }\end{array}$ & 2 & 0.002 \\
\hline GO:0045666 & biological_process & positive regulation of neuron differentiation & 2 & 0.040 \\
\hline GO:0048018 & molecular_function & receptor ligand activity & 2 & 0.022 \\
\hline
\end{tabular}


Extended Data Table 13 | Identification of Teleogryllus oceanicus cuticular hydrocarbon profile peaks using gas chromatography - mass spectrometry

\begin{tabular}{|c|c|c|c|}
\hline Peak $^{a}$ & Kováts retention index ${ }^{b}$ & Identification & Diagnostic ions \\
\hline standard & & pentadecane & \\
\hline 1 & 2840 & $4 \mathrm{MeC}_{28}$ & 365,71 \\
\hline 2 & 2893 & $10 \mathrm{MeC}_{28}$ & 281,155 \\
\hline 3 & 2910 & $13 \mathrm{MeC}_{29}$ & 252,196 \\
\hline 4 & 3028 & $\mathrm{C}_{30: 1}$ & 434 \\
\hline 5 & 3043 & $4 \mathrm{MeC}_{30}$ & $436,393,71$ \\
\hline 6 & 3064 & $7, \mathrm{x}-\mathrm{diMeC}_{30}$ & 365,112 \\
\hline 7 & 3075 & unidentified & \\
\hline 8 & 3086 & $\mathrm{C}_{31: 1}$ & 434 \\
\hline 9 & 3110 & $11 \mathrm{MeC}_{31}$ & 308,168 \\
\hline 10 & 3119 & $7,8 \mathrm{MeC}_{31}$ & 364,112 \\
\hline 11 & 3130 & 7- $\mathrm{C}_{31}$ ene & $434,528^{c}, 145^{c}, 383^{c}$ \\
\hline 12 & 3142 & $\mathrm{C}_{31: 1}$ & 434 \\
\hline 13 & 3152 & $\mathrm{C}_{31: 2}$ & 432 \\
\hline 14 & 3161 & $\mathrm{C}_{31: 2}$ & 432 \\
\hline 15 & 3174 & $\mathrm{C}_{31: 2}$ & 432 \\
\hline 16 & 3188 & $\mathrm{C}_{31: 2}$ & 432 \\
\hline 17 & 3242 & $4 \mathrm{MeC}_{32}$ & 421,71 \\
\hline 18 & 3252 & unidentified & \\
\hline 19 & 3268 & $\mathrm{C}_{32: 2}$ & 446 \\
\hline 20 & 3288 & $\mathrm{C}_{33: 1}$ & 462 \\
\hline 21 & 3331 & $\mathrm{C}_{33: 1}$ & 462 \\
\hline 22 & 3347 & $\mathrm{C}_{33: 2}$ & 460 \\
\hline 23 & 3355 & $\mathrm{C}_{33: 2}$ & 460 \\
\hline 24 & 3365 & $\mathrm{C}_{33: 2}$ & 460 \\
\hline 25 & 3379 & $3, \mathrm{x}-\mathrm{C}_{33: 2}$ & $460,647^{\mathrm{c}}, 89^{\mathrm{c}}$ \\
\hline 26 & 3391 & $\mathrm{C}_{33: 2}$ & 460 \\
\hline
\end{tabular}

${ }^{a}$ Peak identification is based on Table S4 of Pascoal et al. $(2016)^{83}$, reproduced here. The 26 quantified peaks are presented in sequential order in the table and in Fig. 3A of the main text.

${ }^{\mathrm{b}}$ Calculation of the Kováts retention index using $n$-alkane standards $\left(\mathrm{C}_{7}-\mathrm{C}_{40}\right)$ is described in Majlát et al. (1974) ${ }^{99}$

${ }^{\mathrm{c}}$ Ions used when identifying with dimethyl-disulphide derivation 
bioRxiv preprint doi: https://doi.org/10.1101/489526; this version posted December 9, 2018. The copyright holder for this preprint (which was not certified by peer review) is the author/funder, who has granted bioRxiv a license to display the preprint in perpetuity. It is made available under aCC-BY-NC-ND 4.0 International license.

Extended Data Table 14 | Principal components with eigenvalues $>$ 1 from PCA on male CHC profiles; MANOVA results examine the effect of male morph on scores for each PC (multivariate model: Wilks' $\left.\lambda=0.517, F_{6,191}=29.769, p<0.001\right)$.

\begin{tabular}{llllll}
\hline $\begin{array}{l}\text { Principal } \\
\text { component }\end{array}$ & Eigenvalue & $\begin{array}{l}\text { \% Variance } \\
\text { explained }\end{array}$ & $\mathbf{F}_{\mathbf{1 , 1 9 6}}$ & $\mathbf{P}$ & $\mathbf{R}^{\mathbf{2}}$ \\
\hline 1 & 9.408 & 36.18 & 25.885 & $<0.001$ & 0.131 \\
2 & 2.635 & 10.136 & 18.040 & $<0.001$ & 0.092 \\
3 & 2.490 & 9.576 & 21.454 & $<0.001$ & 0.109 \\
4 & 1.888 & 7.261 & 0.001 & 0.979 & 0.000 \\
5 & 1.315 & 5.058 & 25.741 & $<0.001$ & 0.131 \\
6 & 1.020 & 3.925 & 4.079 & 0.043 & 0.021 \\
\hline
\end{tabular}


(A)

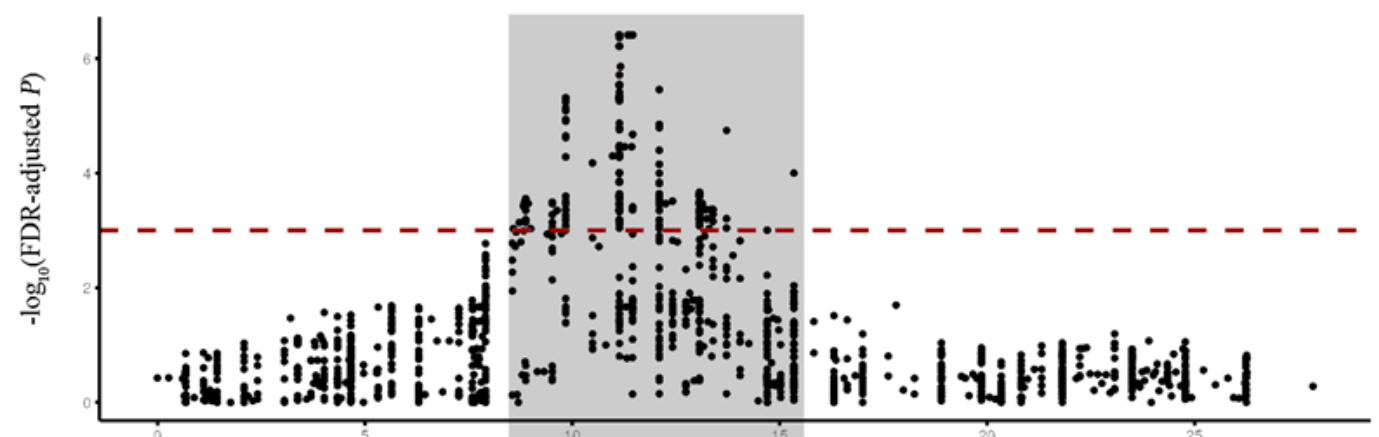

(B)

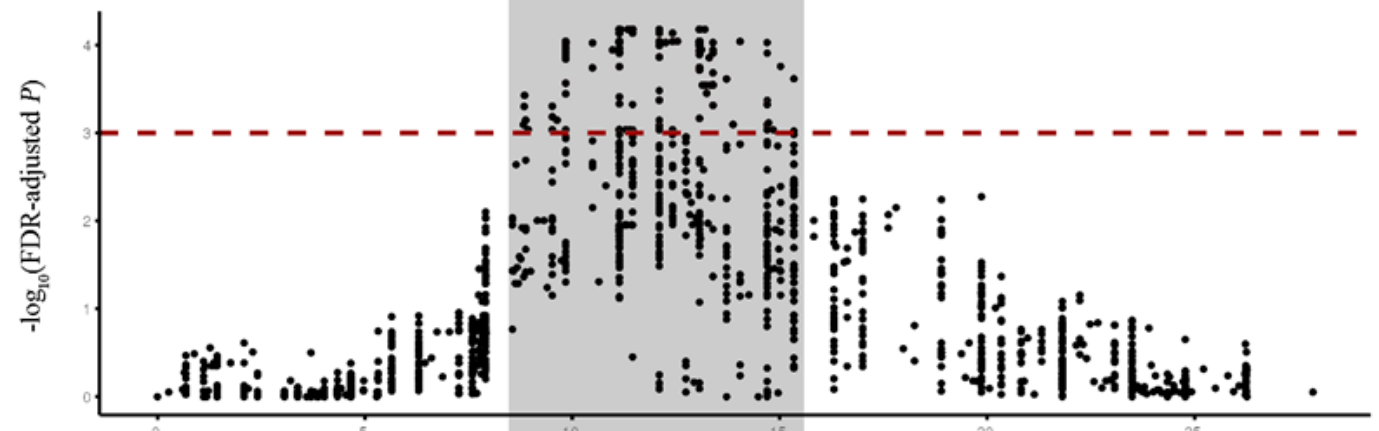

(C)

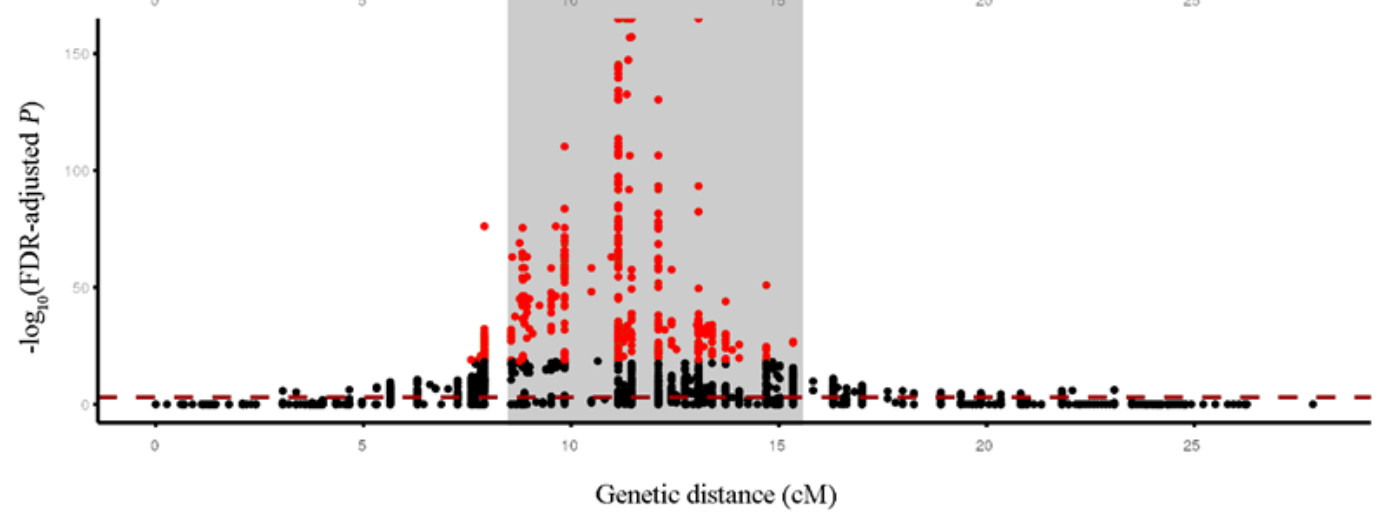

Extended Data Figure 7 | Genomic regions associated with different principal components describing male CHC profiles. Manhattan plot for LG1 (putative X chromosome) showing a, the PC4associated QTL, b, PC6-associated QTL and c, the flatwing QTL for comparison. The horizontal dashed lines indicate FDR-corrected significance threshold of $\mathrm{P}<0.001$, and the top $1 \%$ most significant flatwing-associated QTL markers are plotted in red in c. The light grey rectangle spans the genetic region in which flatwing-associated markers and $\mathrm{CHC}$ principal component-associated markers colocalize. 
Extended Data Table 15 | Candidate gene set associated with each CHC phenotype (individual or principal component) that yielded a significant QTL on the putative X (LG1), with the flatwing QTL for comparison

\begin{tabular}{|c|c|c|c|c|c|c|c|c|c|c|c|c|c|c|c|c|c|c|}
\hline \multirow{2}{*}{\multicolumn{3}{|c|}{ Coordinates }} & \multirow{3}{*}{ Gene ID } & \multicolumn{13}{|c|}{ Trait } & \multirow{3}{*}{\multicolumn{2}{|c|}{ Description }} \\
\hline & & & & \multicolumn{9}{|c|}{ Individual Compounds } & \multicolumn{3}{|c|}{ PCs } & \multirow{2}{*}{$\begin{array}{l}\text { Flat- } \\
\text { wing }\end{array}$} & & \\
\hline Scaffold & Start & Stop & & 1 & 5 & 7 & 8 & 9 & 12 & 15 & 18 & 21 & 1 & 4 & 6 & & & \\
\hline Contig10220_pilon & 78887 & 163134 & TOT000182.1 & $\sqrt{ }$ & $\sqrt{ }$ & $\sqrt{ }$ & $\sqrt{ }$ & & & & $\sqrt{ }$ & $\sqrt{ }$ & & $\sqrt{ }$ & $\sqrt{ }$ & $\sqrt{ }$ & YGD6 & Zinc-type alcohol dehydrogenase-like protein C1773.06c \\
\hline Contig11287_pilon & 199864 & 215783 & ТОT001075.1 & $\sqrt{ }$ & $\sqrt{ }$ & $\sqrt{ }$ & $\sqrt{ }$ & $\sqrt{ }$ & $\sqrt{ }$ & $\sqrt{ }$ & $\sqrt{ }$ & $\sqrt{ }$ & $\sqrt{ }$ & $\sqrt{ }$ & $\sqrt{ }$ & $\sqrt{ }$ & HNF4 & Transcription factor HNF-4 homolog \\
\hline Contig12423_pilon & 12805 & 162659 & TOT001854.1 & $\sqrt{ }$ & $\sqrt{ }$ & $\sqrt{ }$ & $\sqrt{ }$ & $\sqrt{ }$ & $\sqrt{ }$ & $\sqrt{ }$ & $\sqrt{ }$ & $\sqrt{ }$ & $\sqrt{ }$ & $\sqrt{ }$ & $\sqrt{ }$ & $\sqrt{ }$ & OSM3 & Osmotic avoidance abnormal protein 3 \\
\hline Contig14561_pilon & 436209 & 450946 & TOT003337.1 & & & & & & & & $\sqrt{ }$ & & & & & & CAS & Transcription factor castor \\
\hline Contig16800_pilon & 571706 & 708271 & ТОT004499.1 & & & & & & & & $\sqrt{ }$ & & & & & & SMAD3 & Mothers against decapentaplegic homolog 3 \\
\hline Contig17198_pilon & 217974 & 328434 & ТОТ004721.1 & & $\sqrt{ }$ & & & & & & & & & & $\sqrt{ }$ & $\sqrt{ }$ & SCN60 & Sodium channel protein $60 \mathrm{E}$ \\
\hline Contig17198 pilon & 398116 & 526355 & TOT004722.1 & $\sqrt{ }$ & & & & $\sqrt{ }$ & & & $\sqrt{ }$ & & & $\sqrt{ }$ & & $\sqrt{ }$ & SCN60 & Sodium channel protein $60 \mathrm{E}$ \\
\hline Contig17589_pilon & 46372 & 264973 & TOT004897.1 & & & & & & & $\sqrt{ }$ & $\sqrt{ }$ & & & & & & SSBP3 & Single-stranded DNA-binding protein 3 \\
\hline Contig17589 pilon & 70840 & 324258 & TOT004898.1 & & & & & & & $\sqrt{ }$ & $\sqrt{ }$ & & & & & & ATG10 & Ub iquitin-like-conjugating enzyme ATG10 \\
\hline Contig17791_pilon & 294998 & 303418 & TOT005017.1 & $\sqrt{ }$ & $\sqrt{ }$ & & & & & & $\sqrt{ }$ & $\sqrt{ }$ & & & & $\sqrt{ }$ & PKRA & Protein krasavietz \\
\hline Contig18309 pilon & 75967 & 136785 & TOT005266.1 & & $\sqrt{ }$ & & & & & & & & & & & & STA5B & Signal transducer and activator of transcription 5B \\
\hline Contig191692_pilon & 10444 & 19353 & ТОТ005602.1 & & & & & & & & $\sqrt{ }$ & & & & & & GNAI & Guanine nucleotide-binding protein $\mathrm{G}(\mathrm{i})$ subunit alpha \\
\hline Contig20777_pilon & 197732 & 433721 & TOT006213.1 & $\sqrt{ }$ & $\sqrt{ }$ & & & & & $\sqrt{ }$ & $\sqrt{ }$ & $\sqrt{ }$ & $\sqrt{ }$ & $\sqrt{ }$ & & $\sqrt{ }$ & COLL & Transcription factor collier \\
\hline Contig23454_pilon & 18213 & 89940 & TOT006946.1 & & $\sqrt{ }$ & & & & & & $\sqrt{ }$ & & & & & & ARD17 & Arrestin domain-containing protein 17 \\
\hline Contig23647_pilon & 61437 & 289082 & ТОТ006991.1 & $\sqrt{ }$ & $\sqrt{ }$ & $\sqrt{ }$ & $\sqrt{ }$ & & & & $\sqrt{ }$ & $\sqrt{ }$ & & $\sqrt{ }$ & $\sqrt{ }$ & $\sqrt{ }$ & RAVR1 & Ribonucleoprotein PTB-binding 1 \\
\hline Contig24519 pilon & 569981 & 635619 & TOT007221.1 & & & & & & & & $\sqrt{ }$ & & & & & $\sqrt{ }$ & SEPIA & Pyrimidodiazepine synthase \\
\hline Contig27628 pilon & 259968 & 507152 & TOT008051.1 & & & & & & & & $\sqrt{ }$ & & & & & & PROH3 & Prohormone-3 \\
\hline Contig29117_pilon & 70169 & 396634 & TOT008443.1 & & $\sqrt{ }$ & $\sqrt{ }$ & $\sqrt{ }$ & & & & $\sqrt{ }$ & & & & & & CCKAR & Cholecystokinin receptor type A \\
\hline Contig29877_pilon & 36855 & 181557 & ТОT008655.1 & & $\sqrt{ }$ & & & & & & & & & & & & E41LA & Band 4.1-like protein 4A \\
\hline Contig3077_pilon & 487713 & 492969 & ТОТ008894.1 & $\sqrt{ }$ & $\sqrt{ }$ & $\sqrt{ }$ & $\sqrt{ }$ & $\sqrt{ }$ & $\sqrt{ }$ & $\sqrt{ }$ & $\sqrt{ }$ & $\sqrt{ }$ & $\sqrt{ }$ & $\sqrt{ }$ & $\sqrt{ }$ & $\sqrt{ }$ & REXO4 & RNA exonuclease 4 \\
\hline Contig3077_pilon & 528735 & 564924 & TOT008896.1 & & $\sqrt{ }$ & & & & & & & & & & & & $\mathrm{P} 4 \mathrm{~K} 2 \mathrm{~B}$ & Phosphatidylinositol 4-kinase type 2 \\
\hline Contig31374_pilon & 461061 & 489320 & ТОT009067.1 & $\sqrt{ }$ & $\sqrt{ }$ & $\sqrt{ }$ & $\sqrt{ }$ & $\sqrt{ }$ & $\sqrt{ }$ & $\sqrt{ }$ & $\sqrt{ }$ & $\sqrt{ }$ & $\sqrt{ }$ & $\sqrt{ }$ & $\sqrt{ }$ & $\sqrt{ }$ & FRM4B & FERM domain-containing protein 4B \\
\hline Contig32190 pilon & 94344 & 248306 & ТОT009274.1 & $\sqrt{ }$ & $\sqrt{ }$ & $\sqrt{ }$ & $\sqrt{ }$ & & & & $\sqrt{ }$ & $\sqrt{ }$ & & $\sqrt{ }$ & $\sqrt{ }$ & $\sqrt{ }$ & RN207 & RING finger protein 207 \\
\hline Contig3429_pilon & 122631 & 136033 & TOT009790.1 & $\sqrt{ }$ & & & & & & & $\sqrt{ }$ & & & & & & A0A1B6JV12 & Uncharacterized protein \\
\hline Contig3536 pilon & 221796 & 347378 & TOT010046.1 & & $\sqrt{ }$ & & & & & & $\sqrt{ }$ & & & & & & GNAO & Guanine nucleotide-bind ing protein $\mathrm{G}(\mathrm{o})$ subunit alpha \\
\hline Contig35402 pilon & 14084 & 125884 & TOT010060.1 & & $\sqrt{ }$ & $\sqrt{ }$ & & & & & $\sqrt{ }$ & & & $\sqrt{ }$ & $\sqrt{ }$ & $\sqrt{ }$ & ABCG1 & ATP-binding cassette sub-family $\mathrm{G}$ member 1 \\
\hline Contig3552_pilon & 175659 & 203623 & ТОТ010094.1 & & $\sqrt{ }$ & & & & & & $\sqrt{ }$ & & & & & & OSBL9 & Oxysterol-binding protein-related protein 9 \\
\hline Contig37346_pilon. 1 & 133394 & 180067 & TOT010542.1 & $\sqrt{ }$ & $\sqrt{ }$ & $\sqrt{ }$ & $\sqrt{ }$ & $\sqrt{ }$ & $\sqrt{ }$ & $\sqrt{ }$ & $\sqrt{ }$ & $\sqrt{ }$ & $\sqrt{ }$ & $\sqrt{ }$ & $\sqrt{ }$ & $\sqrt{ }$ & SCYL1 & $\mathrm{N}$-terminal kinase-like protein \\
\hline Contig40569_pilon & 70324 & 81832 & ТОТ011293.1 & $\sqrt{ }$ & & & & & & & $\sqrt{ }$ & & & & & & NXT1 & NTF2-related export protein \\
\hline Contig43774_pilon & 63974 & 228355 & TOT011905.1 & & & & & & & & $\sqrt{ }$ & & & & & & HMCN1 & Hemicentin-1 \\
\hline Contig4430_pilon & 60074 & 108676 & TOT012009.1 & $\sqrt{ }$ & $\sqrt{ }$ & $\sqrt{ }$ & & & & $\sqrt{ }$ & $\sqrt{ }$ & $\sqrt{ }$ & $\sqrt{ }$ & & & $\sqrt{ }$ & LAR & Tyrosine-protein phosphatase Lar \\
\hline Contig4451_pilon & 20121 & 45182 & TOT012039.1 & & $\sqrt{ }$ & & & & & & & & & & & & LAR4 & La-related protein Larp4B \\
\hline Contig48084_pilon & 4534 & 15580 & ТОT012711.1 & & $\sqrt{ }$ & & & & & & $\sqrt{ }$ & & & & & $\sqrt{ }$ & KPEL & Serine/threonine-protein kinase pelle \\
\hline Contig48322 pilon & 73569 & 78934 & TOT012764.1 & & & & & & & & $\sqrt{ }$ & & & & & $\sqrt{ }$ & CAH10 & Carbonic anhydrase-related protein 10 \\
\hline Contig5051_pilon & 34769 & 44241 & ТОT013154.1 & & & & & & & & $\sqrt{ }$ & & & & & & CMYA5 & Cardiomyopathy-associated protein 5 \\
\hline
\end{tabular}

Pascoal et al. | Genomic Footprint of Recent Adaptive Trait Loss | Page $\mathbf{1}$ of $\mathbf{5 2}$ 


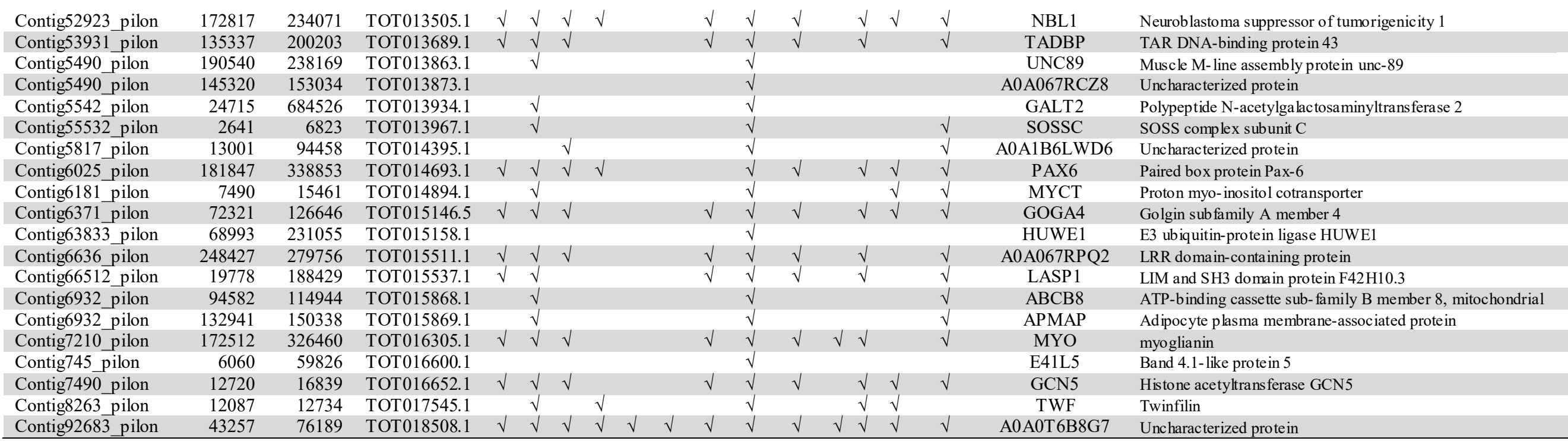


bioRxiv preprint doi: https://doi.org/10.1101/489526; this version posted December 9,2018 . The copyright holder for this preprint (which was not certified by peer review) is the author/funder, who has granted bioRxiv a license to display the preprint in perpetuity. It is made available under aCC-BY-NC-ND 4.0 International license.

Extended Data Table 16 | Allele replacement table for identifying the $\mathrm{X}$ chromosome in the T. oceanicus linkage map

\begin{tabular}{llllllll}
\hline Dam & Sire & $\begin{array}{l}\text { Sire } \\
\text { assumed }\end{array}$ & $\begin{array}{l}\text { Sire } \\
\text { rewrite }\end{array}$ & $\begin{array}{l}\text { male } \\
\text { current }\end{array}$ & $\begin{array}{l}\text { male } \\
\text { rewrite }\end{array}$ & $\begin{array}{l}\text { male } \\
\text { current }\end{array}$ & $\begin{array}{l}\text { male } \\
\text { rewrite }\end{array}$ \\
\hline $\mathbf{0} / \mathbf{1}$ & $0 / 0$ & $0 /$. & $0 / 2$ & $0 / 0$ & $0 / 2$ & $1 / 1$ & $1 / 2$ \\
$\mathbf{0} / \mathbf{1}$ & $1 / 1$ & $1 /$. & $1 / 2$ & $0 / 0$ & $0 / 2$ & $1 / 1$ & $1 / 2$ \\
$\mathbf{0} / \mathbf{1}$ & $2 / 2$ & $2 /$. & $\mathrm{NA}$ & - & - & - & - \\
$\mathbf{0} / \mathbf{2}$ & $0 / 0$ & $0 /$. & $0 / 1$ & $0 / 0$ & $0 / 1$ & $2 / 2$ & $1 / 2$ \\
$\mathbf{0} / \mathbf{2}$ & $1 / 1$ & $1 /$. & $\mathrm{NA}$ & - & - & - & - \\
$\mathbf{0} / \mathbf{2}$ & $2 / 2$ & $2 /$. & $2 / 1$ & $0 / 0$ & $0 / 1$ & $2 / 2$ & $2 / 1$ \\
$\mathbf{1} / \mathbf{2}$ & $0 / 0$ & $0 /$. & $\mathrm{NA}$ & - & - & - & - \\
$\mathbf{1} / \mathbf{2}$ & $1 / 1$ & $1 /$. & $1 / 3$ & $1 / 1$ & $1 / 3$ & $2 / 2$ & $2 / 3$ \\
$\mathbf{1} / \mathbf{2}$ & $2 / 2$ & $2 /$. & $2 / 3$ & $1 / 1$ & $1 / 3$ & $2 / 2$ & $2 / 3$ \\
\hline
\end{tabular}



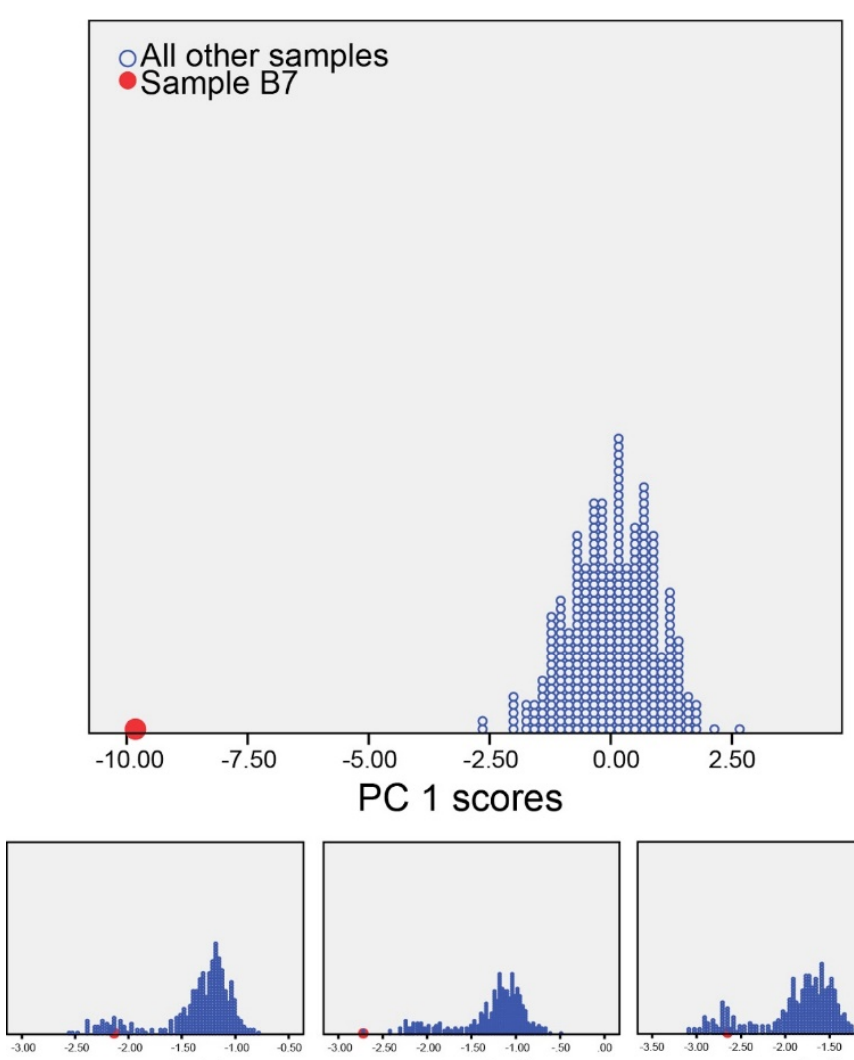

peak_7

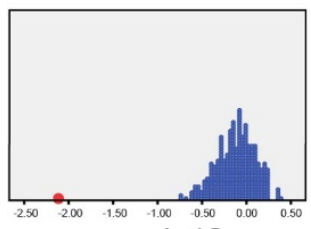

peak 12

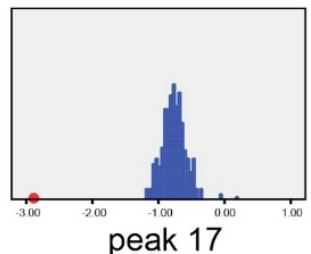

peak 17

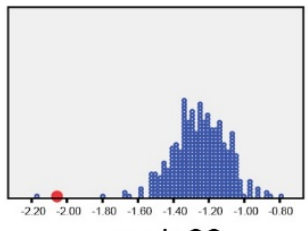

peak 22

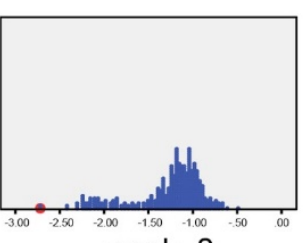

peak_8

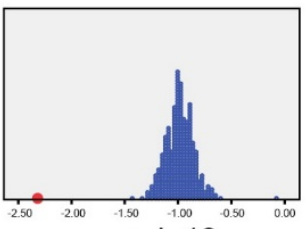

peak 13
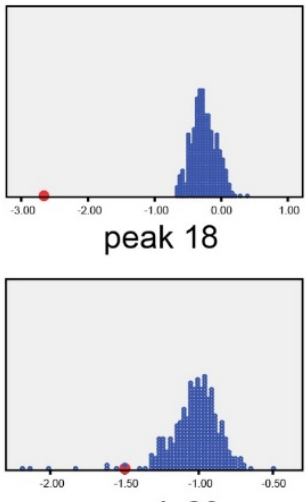

peak 23

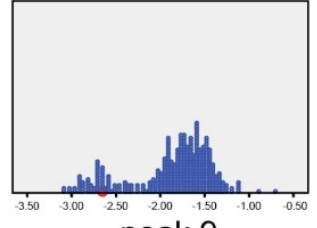

peak 9

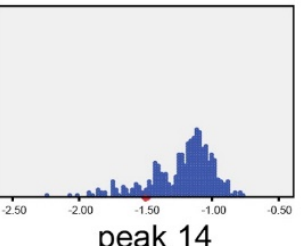

peak 14
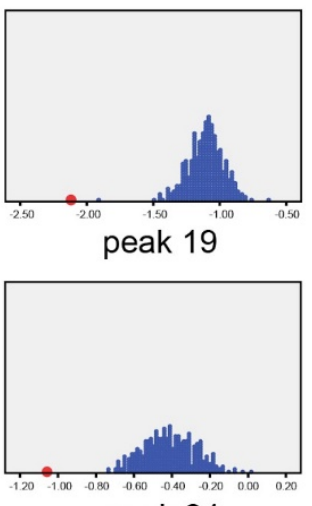

peak 24
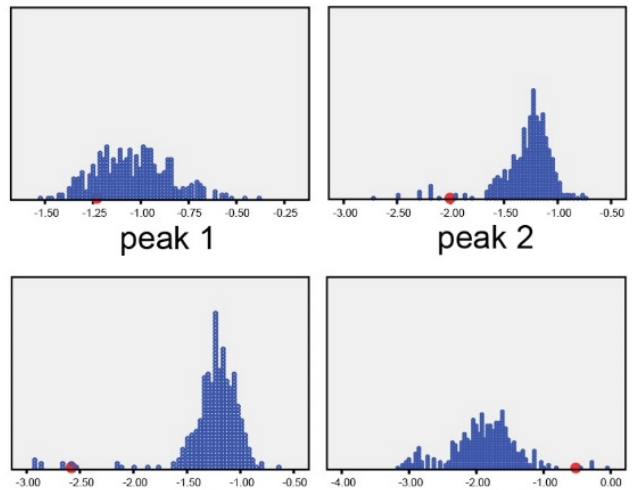

peak 3
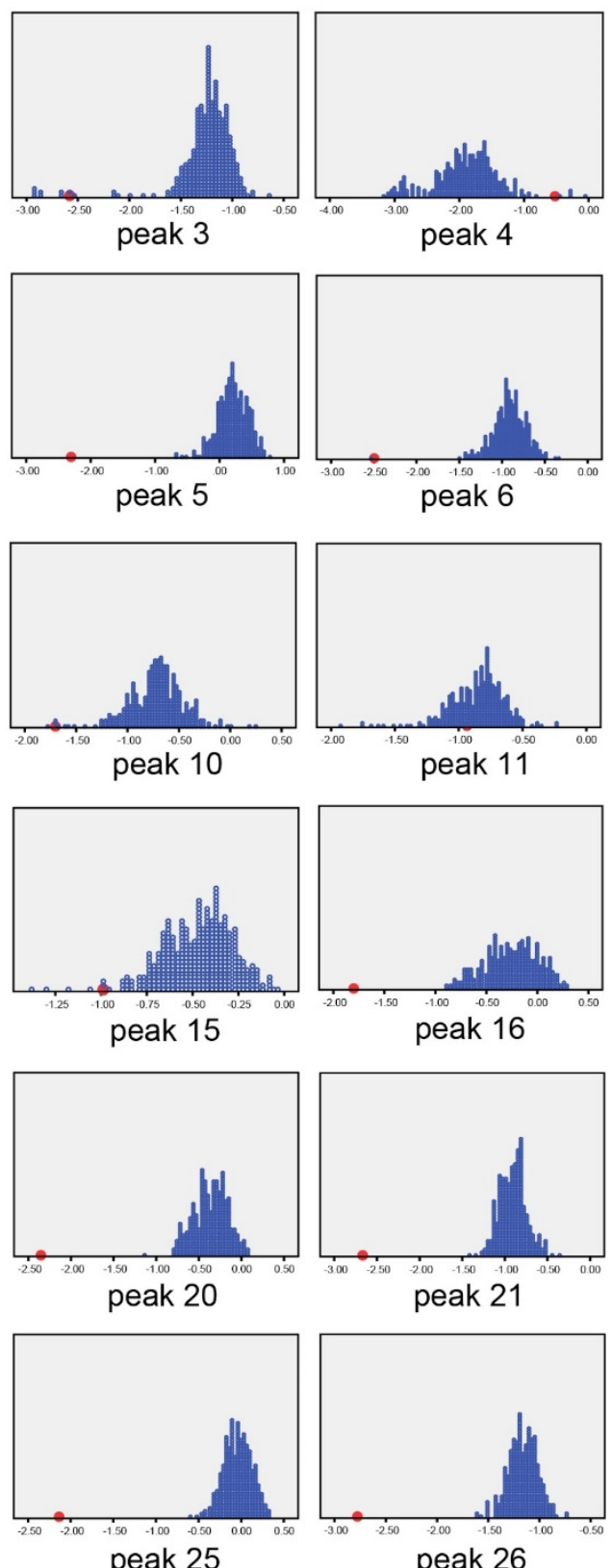

Extended Data Figure 8 | Histograms illustrating the identification of a CHC sample outlier. Sample B7, a normal-wing male, is indicated by the enlarged red dot in each plot. The sample was observed on visual inspection to deviate substantially from the distribution of principal component 1 scores for all other mapping individuals. Further inspection revealed this also to be the case in the majority of cases when the sample was assessed for each CHC peak individually. It was thus excluded from further analysis. 
Acknowledgements The Natural Environment Research Council provided funding to N.W.B. (NE/G014906/1, NE/L011255/1), and to N.W.B. and M.G.R. (NE/1027800/1). Sequencing support was provided by Edinburgh Genomics and the Centre for Genomic Research at the University of Liverpool. Bioinformatics resources at St Andrews were funded by a Wellcome Trust ISSF award (105621/Z/14/Z). Support from the China Scholarship Council (201703780018) to X.Z. is gratefully acknowledged. The Biotechnology and Biological Sciences Research Council provided support to M.B. which aided in the development of ChirpBase (BB/K020161/1). We thank J. Kenny for NGS sequencing advice; Y. Fang for read processing; R. Fallon for bioinformatics assistance; J.Q. Liu and K. Wang for advice regarding gene prediction pipelines; J. Bastiaansen and P. Gienapp for assistance with ASReml, W.V. Bailey, B. Gray, J.T. Rotenberry, S. Vardy and M. Zuk for assistance in the field; D. Forbes, A. Grant and T. Sneddon for assistance in the laboratory; C. Mitchell for assistance with $\mathrm{CHC}$ analyses.

Author contributions N.W.B. conceived and led the study. S.P., K.G., M.B., M.G.R. and N.W.B. designed experiments. S.P. led data collection. S.P. did genetic crosses and wet lab work. S.P., J.E.R., X.Z., T.C., E.L., X.L., J.H., J.G.R., B.L.S., U.T. and N.W.B. performed analyses. M.B., R.J.C., S.J., E.L., M.B. and N.W.B. designed ChirpBase. N.W.B. led manuscript writing. S.P., J.E.R., X.Z., E.L., M.B., M.G.R. and N.W.B contributed to writing.

Competing interests The authors declare no competing interests.

\section{References}

1. Wiens, J. J. Widespread loss of sexually selected traits: how the peacock lost its spots. Trends in Ecology \& Evolution 16, 517-523 (2001).

2. Whiting, M. F., Bradler, S. \& Maxwell, T. Loss and recovery of wings in stick insects. Nature 421, $264-$ 267 (2003).

3. Nadeau, J. H. et al. Pleiotropy, homeostasis, and functional networks based on assays of cardiovascular traits in genetically randomized populations. Genome Res 13, 2082-2091 (2003).

4. Zuk, M., Rotenberry, J. T. \& Tinghitella, R. M. Silent night: adaptive disappearance of a sexual signal in a parasitized population of field crickets. Biol Lett 2, 521-524 (2006).

5. Zuk, M., Bailey, N. W., Gray, B. \& Rotenberry, J. T. Sexual signal loss: The link between behaviour and rapid evolutionary dynamics in a field cricket. J Anim Ecol 87, 623-633 (2018).

6. Tinghitella, R. M. Rapid evolutionary change in a sexual signal: genetic control of the mutation 'flatwing' that renders male field crickets (Teleogryllus oceanicus) mute. Heredity 100, 261-267 (2008).

7. Pascoal, S. et al. Rapid convergent evolution in wild crickets. Curr Biol 24, 1369-1374 (2014).

8. Fisher, R. The Genetical Theory of Natural Selection. 1st edn, (The Clarendon Press, 1930).

9. Orr, H. A. The genetic theory of adaptation: a brief history. Nat Rev Genet 6, 119-127 (2005).

10. Hartley, C. J. et al. Amplification of DNA from preserved specimens shows blowflies were preadapted for the rapid evolution of insecticide resistance. Proc Natl Acad Sci U S A 103, 8757-8762 (2006).

11. Raymond, M., Berticat, C., Weill, M., Pasteur, N. \& Chevillon, C. Insecticide resistance in the mosquito Culex pipiens: what have we learned about adaptation? Genetica 112-113, 287-296 (2001).

12. van't Hof, A. E., Edmonds, N., Dalikova, M., Marec, F. \& Saccheri, I. J. Industrial melanism in British peppered moths has a singular and recent mutational origin. Science 332, 958-960 (2011).

13. Van't Hof, A. E. et al. The industrial melanism mutation in British peppered moths is a transposable element. Nature 534, 102-105 (2016).

14. True, J. R. Insect melanism: the molecules matter. Trends in Ecology \& Evolution 18, 640-647 (2003).

15. Challis, R. J., Kumar, S., Stevens, L. \& Blaxter, M. GenomeHubs: simple containerized setup of a custom Ensembl database and web server for any species. Database (Oxford) 2017,

Pascoal et al. | Genomic Footprint of Recent Adaptive Trait Loss | Page $\mathbf{3}$ of $\mathbf{5 2}$ 
doi:10.1093/database/bax039 (2017).

16. Snodgrass, R. E. Principles of Insect Morphology (Cornell University Press, 1993).

17. De Celis, J. F. Pattern formation in the Drosophila wing: The development of the veins. Bioessays 25, 443-451 (2003).

18. Hatini, V., Kula-Eversole, E., Nusinow, D. \& Del Signore, S. J. Essential roles for stat92E in expanding and patterning the proximodistal axis of the Drosophila wing imaginal disc. Dev Biol 378, 38-50 (2013).

19. Vervoort, M., Crozatier, M., Valle, D. \& Vincent, A. The COE transcription factor Collier is a mediator of short-range Hedgehog-induced patterning of the Drosophila wing. Curr Biol 9, 632-639 (1999).

20. Hevia, C. F. \& de Celis, J. F. Activation and function of TGFbeta signalling during Drosophila wing development and its interactions with the BMP pathway. Dev Biol 377, 138-153 (2013).

21. Bicocca, V. T. et al. Crosstalk between ROR1 and the Pre-B cell receptor promotes survival of $t(1 ; 19)$ acute lymphoblastic leukemia. Cancer Cell 22, 656-667 (2012).

22. Carvajal-Gonzalez, J. M., Mulero-Navarro, S., Smith, M. \& Mlodzik, M. A novel Frizzled-based screening tool identifies genetic modifiers of planar cell polarity in Drosophila wings. G3 (Bethesda) 6, 3963-3973 (2016).

23. Adler, P. N. The frizzled/stan pathway and planar cell polarity in the Drosophila wing. Curr Top Dev Biol 101, 1-31 (2012).

24. Wu, C. et al. Pelle modulates dFoxO-mediated cell death in Drosophila. Plos Genet 11, e1005589, doi:10.1371/journal.pgen.1005589 (2015).

25. Carre, C., Szymczak, D., Pidoux, J. \& Antoniewski, C. The histone H3 acetylase dGcn5 is a key player in Drosophila melanogaster metamorphosis. Mol Cell Biol 25, 8228-8238 (2005).

26. Okada, H., Ebhardt, H. A., Vonesch, S. C., Aebersold, R. \& Hafen, E. Proteome-wide association studies identify biochemical modules associated with a wing-size phenotype in Drosophila melanogaster. Nat Commun 7, 12649, doi:10.1038/ncomms12649 (2016).

27. Tregenza, T. \& Wedell, N. Definitive evidence for cuticular pheromones in a cricket. Anim Behav 54, 979-984 (1997).

28. Thomas, M. L. \& Simmons, L. W. Sexual selection on cuticular hydrocarbons in the Australian field cricket, Teleogryllus oceanicus. BMC Evol Biol 9, 162, doi:10.1186/1471-2148-9-162 (2009).

29. Thomas, M. L. \& Simmons, L. W. Cuticular hydrocarbons influence female attractiveness to males in the Australian field cricket, Teleogryllus oceanicus. J Evol Biol 23, 707-714 (2010).

30. Simmons, L. W., Thomas, M. L., Gray, B. \& Zuk, M. Replicated evolutionary divergence in the cuticular hydrocarbon profile of male crickets associated with the loss of song in the Hawaiian archipelago. $J$ Evol Biol 27, 2249-2257 (2014).

31. Gray, B., Bailey, N. W., Poon, M. \& Zuk, M. Multimodal signal compensation: do field crickets shift sexual signal modality after the loss of acoustic communication? Animal behaviour 93, 243-248 (2014).

32. Dugatkin, L. A. Principles of Animal Behavior. 2nd edn, (W. W. Norton \& Company, 2008).

33. Bank, C., Hietpas, R. T., Wong, A., Bolon, D. N. \& Jensen, J. D. A bayesian MCMC approach to assess the complete distribution of fitness effects of new mutations: uncovering the potential for adaptive walks in challenging environments. Genetics 196, 841-852 (2014).

34. Pascoal, S. et al. Rapid evolution and gene expression: a rapidly evolving Mendelian trait that silences field crickets has widespread effects on mRNA and protein expression. J Evol Biol 29, 1234-1246 (2016).

35. Bailey, N. W., Gray, B. \& Zuk, M. Acoustic experience shapes alternative mating tactics and reproductive investment in male field crickets. Curr Biol 20, 845-849 (2010).

36. Pascoal, S. et al. Increased socially mediated plasticity in gene expression accompanies rapid adaptive evolution. Ecol Lett 21, 546-556 (2018).

37. Kupper, C. et al. A supergene determines highly divergent male reproductive morphs in the ruff. Nat Genet 48, 79-83 (2016).

38. Joag, R. et al. Transcriptomics of intralocus sexual conflict: Gene expression patterns in females change in response to selection on a male secondary sexual trait in the bulb mite. Genome Biol Evol 8, 2351-2357 (2016).

39. Martin, M. Cutadapt removes adapter sequences from high-throughput sequencing reads. EMBnet. journal 17, pp. 10-12 (2011).

40. Heo, Y., Wu, X. L., Chen, D., Ma, J. \& Hwu, W. M. BLESS: bloom filter-based error correction solution 
for high-throughput sequencing reads. Bioinformatics 30, 1354-1362 (2014).

41. Rognes, T., Flouri, T., Nichols, B., Quince, C. \& Mahe, F. VSEARCH: a versatile open source tool for metagenomics. PeerJ 4, e2584, doi:10.7717/peerj.2584 (2016).

42. Kajitani, R. et al. Efficient de novo assembly of highly heterozygous genomes from whole-genome shotgun short reads. Genome Res 24, 1384-1395 (2014).

43. English, A. C. et al. Mind the gap: upgrading genomes with Pacific Biosciences RS long-read sequencing technology. PLoS One 7, e47768, doi:10.1371/journal.pone.0047768 (2012).

44. Walker, B. J. et al. Pilon: an integrated tool for comprehensive microbial variant detection and genome assembly improvement. PLoS One 9, e112963, doi:10.1371/journal.pone. 0112963 (2014).

45. Simao, F. A., Waterhouse, R. M., loannidis, P., Kriventseva, E. V. \& Zdobnov, E. M. BUSCO: assessing genome assembly and annotation completeness with single-copy orthologs. Bioinformatics 31, 32103212 (2015).

46. Tarailo-Graovac, M. \& Chen, N. Using RepeatMasker to identify repetitive elements in genomic sequences. Curr Protoc Bioinformatics Chapter 4, Unit 4 10, doi:10.1002/ 0471250953.bi0410s25 (2009).

47. Price, A. L., Jones, N. C. \& Pevzner, P. A. De novo identification of repeat families in large genomes. Bioinformatics 21 Suppl 1, i351-358, doi:21/suppl_1/i351 (2005).

48. Hubley, R. et al. The Dfam database of repetitive DNA families. Nucleic Acids Res 44, D81-89, doi:10.1093/nar/gkv1272(2016).

49. Bao, W., Kojima, K. K. \& Kohany, O. Repbase Update, a database of repetitive elements in eukaryotic genomes. Mob DNA 6, 11, doi:10.1186/s13100-015-0041-9 (2015).

50. Boratyn, G. M. et al. Domain enhanced lookup time accelerated BLAST. Biol Direct 7, 12, doi:10.1186/1745-6150-7-12 (2012).

51. Smit, A., Hubley, R. \& Green, P. RepeatMasker Open-4.0, <http://www.repeatmasker.org> (20132015).

52. Abrusan, G., Grundmann, N., DeMester, L. \& Makalowski, W. TEclass--a tool for automated classification of unknown eukaryotic transposable elements. Bioinformatics 25, 1329-1330 (2009).

53. Benson, G. Tandem repeats finder: a program to analyze DNA sequences. Nucleic Acids Res 27, 573580 (1999).

54. Korf, I. Gene finding in novel genomes. BMC Bioinformatics 5, 59, doi:10.1186/1471-2105-5-59 (2004).

55. Majoros, W. H., Pertea, M. \& Salzberg, S. L. TigrScan and GlimmerHMM: two open source ab initio eukaryotic gene-finders. Bioinformatics 20, 2878-2879 (2004).

56. Blanco, E., Parra, G. \& Guigo, R. Using geneid to identify genes. Curr Protoc Bioinformatics Chapter 4, Unit 4 3, doi:10.1002/0471250953.bi0403s18 (2007).

57. Hoff, K. J., Lange, S., Lomsadze, A., Borodovsky, M. \& Stanke, M. BRAKER1: Unsupervised RNA-SeqBased Genome Annotation with GeneMark-ET and AUGUSTUS. Bioinformatics 32, 767-769 (2016).

58. Kim, D. et al. TopHat2: accurate alignment of transcriptomes in the presence of insertions, deletions and gene fusions. Genome Biol 14, R36, doi:10.1186/gb-2013-14-4-r36 (2013).

59. Li, H. et al. The Sequence Alignment/Map format and SAMtools. Bioinformatics 25, 2078-2079 (2009).

60. Lomsadze, A., Burns, P. D. \& Borodovsky, M. Integration of mapped RNA-Seq reads into automatic training of eukaryotic gene finding algorithm. Nucleic Acids Res 42, e119, doi:10.1093/nar/gku557 (2014).

61. Stanke, M., Diekhans, M., Baertsch, R. \& Haussler, D. Using native and syntenically mapped cDNA alignments to improve de novo gene finding. Bioinformatics 24, 637-644 (2008).

62. Wang, X. et al. The locust genome provides insight into swarm formation and long-distance flight. Nat Commun 5, 2957, doi:10.1038/ncomms3957 (2014).

63. The International Aphid Genomics Consortium. Genome sequence of the pea aphid Acyrthosiphon pisum. PLoS Biol 8, e1000313, doi:10.1371/journal.pbio.1000313 (2010).

64. Gramates, L. S. et al. FlyBase at 25: looking to the future. Nucleic Acids Res 45, D663-D671, doi:10.1093/nar/gkw1016 (2017).

65. McKenna, D. D. et al. Genome of the Asian longhorned beetle (Anoplophora glabripennis), a globally significant invasive species, reveals key functional and evolutionary innovations at the beetle-plant interface. Genome Biol 17, 227, doi:10.1186/s13059-016-1088-8 (2016).

66. Xue, J. et al. Genomes of the rice pest brown planthopper and its endosymbionts reveal complex complementary contributions for host adaptation. Genome Biol 15, 521, doi:10.1186/s13059-0140521-0 (2014). 
67. Benoit, J. B. et al. Unique features of a global human ectoparasite identified through sequencing of the bed bug genome. Nat Commun 7, 10165, doi:10.1038/ncomms10165 (2016).

68. Suyama, M., Torrents, D. \& Bork, P. BLAST2GENE: a comprehensive conversion of BLAST output into independent genes and gene fragments. Bioinformatics 20, 1968-1970 (2004).

69. Birney, E., Clamp, M. \& Durbin, R. GeneWise and Genomewise. Genome Res 14, 988-995 (2004).

70. Grabherr, M. G. et al. Full-length transcriptome assembly from RNA-Seq data without a reference genome. Nat Biotechnol 29, 644-652 (2011).

71. Xu, Y., Wang, X., Yang, J., Vaynberg, J. \& Qin, J. PASA--a program for automated protein NMR backbone signal assignment by pattern-filtering approach. J Biomol NMR 34, 41-56 (2006).

72. Haas, B. J. et al. Automated eukaryotic gene structure annotation using EVidenceModeler and the Program to Assemble Spliced Alignments. Genome Biol 9, R7, doi:10.1186/gb-2008-9-1-r7 (2008).

73. Yang, Y. et al. Draft genome of the Marco Polo Sheep (Ovis ammon polii). GigaScience 6, 1-7, doi:10.1093/gigascience/gix106 (2017).

74. Finn, R. D. et al. InterPro in 2017-beyond protein family and domain annotations. Nucleic Acids Res 45, D190-D199, doi:10.1093/nar/gkw1107 (2017).

75. Bairoch, A. \& Apweiler, R. The SWISS-PROT protein sequence database and its supplement TrEMBL in 2000. Nucleic Acids Res 28, 45-48 (2000).

76. Jones, P. et al. InterProScan 5: genome-scale protein function classification. Bioinformatics 30, 12361240 (2014).

77. The Gene Ontology Consortium. Expansion of the Gene Ontology knowledgebase and resources. Nucleic Acids Res 45, D331-D338, doi:10.1093/nar/gkw1108 (2017).

78. Adams, M. D. et al. The genome sequence of Drosophila melanogaster. Science 287, 21852195 (2000).

79. Gotz, S. et al. High-throughput functional annotation and data mining with the Blast2GO suite. Nucleic Acids Res 36, 3420-3435 (2008).

80. Kanehisa, M., Sato, Y. \& Morishima, K. BlastKOALA and GhostKOALA: KEGG tools for functional characterization of genome and metagenome sequences. J Mol Biol 428, 726-731 (2016).

81. Tang, H. et al. ALLMAPS: robust scaffold ordering based on multiple maps. Genome Biol 16, 3, doi:10.1186/s13059-014-0573-1 (2015).

82. Kent, W. J. et al. The human genome browser at UCSC. Genome Res 12, 996-1006 (2002).

83. Pascoal, S. et al. Sexual selection and population divergence I: The influence of socially flexible cuticular hydrocarbon expression in male field crickets (Teleogryllus oceanicus). Evolution 70, 82-97 (2016).

84. Catchen, J., Hohenlohe, P. A., Bassham, S., Amores, A. \& Cresko, W. A. Stacks: an analysis tool set for population genomics. Mol Ecol 22, 3124-3140 (2013).

85. Li, H. \& Durbin, R. Fast and accurate short read alignment with Burrows-Wheeler transform. Bioinformatics 25, 1754-1760 (2009).

86. Calus, M. P. Genomic breeding value prediction: methods and procedures. Animal 4, 157-164 (2010).

87. VanRaden, P. M. Efficient methods to compute genomic predictions. J Dairy Sci 91, 4414-4423 (2008).

88. Donoughe, S. \& Extavour, C. G. Embryonic development of the cricket Gryllus bimaculatus. Dev Biol 411, 140-156 (2016).

89. Joshi, N. A. \& Fass, J. N. SICKLE: a sliding-window, adaptive, quality-based trimming tool for FastQ files [Software], <https://github.com/najoshi/sickle> (2011).

90. Pertea, M., Kim, D., Pertea, G. M., Leek, J. T. \& Salzberg, S. L. Transcript-level expression analysis of RNA-seq experiments with HISAT, StringTie and Ballgown. Nat Protoc 11, 1650- 1667 (2016).

91. Robinson, M. D., McCarthy, D. J. \& Smyth, G. K. edgeR: a Bioconductor package for differential expression analysis of digital gene expression data. Bioinformatics 26, 139-140 (2010).

92. Kanehisa, M., Sato, Y., Kawashima, M., Furumichi, M. \& Tanabe, M. KEGG as a reference resource for gene and protein annotation. Nucleic Acids Res 44, D457-462, doi:10.1093/ nar/gkv1070 (2016).

93. Schneider, W. T., Rutz, C., Hedwig, B. \& Bailey, N. W. Vestigial singing behaviour persists after the evolutionary loss of song in crickets. Biol Lett 14, doi:10.1098/rsbl.2017.0654 (2018).

94. Li, S. et al. The genomic and functional landscapes of developmental plasticity in the American cockroach. Nat Commun 9, 1008, doi:10.1038/s41467-018-03281-1 (2018).

95. Rosenfeld, J. A. et al. Genome assembly and geospatial phylogenomics of the bed bug Cimex lectularius. Nat Commun 7, 10164, doi:10.1038/ncomms10164 (2016).

96. Terrapon, N. et al. Molecular traces of alternative social organization in a termite genome. Nat 
bioRxiv preprint doi: https://doi.org/10.1101/489526; this version posted December 9,2018 . The copyright holder for this preprint (which was not certified by peer review) is the author/funder, who has granted bioRxiv a license to display the preprint in perpetuity. It is made available under aCC-BY-NC-ND 4.0 International license.

Commun 5, 3636, doi:10.1038/ncomms4636 (2014).

97. Dudchenko, O. et al. De novo assembly of the Aedes aegypti genome using Hi-C yields chromosomelength scaffolds. Science 356, 92-95 (2017).

98. Miller, J. R. et al. Analysis of the Aedes albopictus C6/36 genome provides insight into cell line utility for viral propagation. GigaScience 7, 1-13, doi:10.1093/gigascience/gix135 (2018).

99. Majlat, P., Erdos, Z. \& Takacs, J. Calculation and application of retention indexes in programmedtemperature gas-chromatography. J Chromatogr 91, 89-103 (1974). 